\title{
Fat-Soluble Vitamins and the Current Global Pandemic of COVID-19: Evidence-Based Efficacy from Literature Review
}

\author{
Nandeeta Samad, (iD) ' Siddhartha \\ Dutta, (iD ${ }^{2}$ Temitayo Eniola \\ Sodunke, (ID) ${ }^{3}$ Adiba Fairuz, ${ }^{4}$ \\ Ashmita Sapkota, (iD) ${ }^{5}$ Zannatul Ferdous \\ Miftah, (iD) ${ }^{6}$ Iffat Jahan, (iD) ${ }^{7}$ \\ Paras Sharma, iD ${ }^{8}$ \\ Abdullahi Rabiu Abubakar, (D) ${ }^{9}$ \\ Adekunle Babajide Rowaiye, (D) ${ }^{10}$ \\ Angus Nnamdi Oli, (iD) ${ }^{10}$ \\ Jaykaran Charan, (iD ${ }^{2}$ \\ Salequl Islam, (D) "Mainul Haque (D) 12 \\ 'Department of Public Health, North South \\ University, Dhaka, 1229, Bangladesh; \\ ${ }^{2}$ Department of Pharmacology, All India Institute \\ of Medical Sciences, Jodhpur, Rajasthan, India; \\ ${ }^{3}$ Department of Anatomy, University of llorin, \\ Nigeria; ${ }^{4}$ Department of Pharmacy, University of \\ Dhaka, Dhaka, Bangladesh; ${ }^{5}$ Department of \\ Microbiology, Faculty of Medicine Siriraj Hospital, \\ Mahidol University, Bangkok, 10700, Thailand; \\ ${ }^{6}$ Department of Nutrition and Food Science, \\ University of Dhaka, Dhaka, Bangladesh; \\ ${ }^{7}$ Department of Physiology, Eastern Medical \\ College, Cumilla, Bangladesh; ${ }^{8}$ Department of \\ Pharmacognosy, BVM College of Pharmacy, \\ Gwalior, India; ${ }^{9}$ Department of Pharmacology \\ and Therapeutics, Faculty of Pharmaceutical \\ Sciences, Bayero University, Kano, Nigeria; \\ ${ }^{10}$ Department of Pharmaceutical Microbiology \\ and Biotechnology, Faculty of Pharmaceutical \\ Sciences, Nnamdi Azikiwe University, Awka, \\ Anambra State, Nigeria; "'Department of \\ Microbiology, Jahangirnagar University, Savar, \\ Dhaka, Bangladesh; ${ }^{12}$ Unit of Pharmacology, \\ Faculty of Medicine and Defence Health, \\ Universiti Pertahanan Nasional Malaysia \\ (National Defence University of Malaysia), Kuala \\ Lumpur, Malaysia
}

Correspondence: Mainul Haque Unit of Pharmacology, Faculty of Medicine and Defence Health, Universiti Pertahanan Nasional Malaysia (National Defence University of Malaysia), Kem Perdana Sungai Besi, Kuala Lumpur, 57000, Malaysia

Tel +60109265543

Email runurono@gmail.com

\begin{abstract}
The outbreak of pneumonia caused by severe acute respiratory syndrome coronavirus-2 (SARS-CoV-2), later named COVID-19 by the World Health Organization (WHO), was initiated at Wuhan, Hubei, China, and there was a rapid spread of novel SARS-CoV-2 and the disease COVID-19 in late 2019. The entire world is now experiencing the challenge of COVID-19 infection. However, still very few evidence-based treatment options are available for the prevention and treatment of COVID-19 disease. The present review aims to summarize the publicly available information to give a comprehensive yet balanced scientific overview of all the fat-soluble vitamins concerning their role in SARSCoV-2 virus infection. The roles of different fat-soluble vitamins and micronutrients in combating SARS-CoV-2 infection have been recently explored in several studies. There are various hypotheses to suggest their use to minimize the severity of COVID-19 infection. These vitamins are pivotal in the maintenance and modulation of innate and cell-mediated, and antibody-mediated immune responses. The data reported in recent literature demonstrate that deficiency in one or more of these vitamins compromises the patients' immune response and makes them more vulnerable to viral infections and perhaps worse disease prognosis. Vitamins A, D, E, and K boost the body's defense mechanism against COVID-19 infection and specifically prevent its complications such as cytokine storm and other inflammatory processes, leading to increased morbidity and mortality overemphasis. However, more detailed randomized double-blind clinical pieces of evidence are required to define the use of these supplements in preventing or reducing the severity of the COVID-19 infection.
\end{abstract}

Keywords: SARS-CoV-2, COVID-19, fat-soluble vitamins, micronutrients, immune response

\section{Introduction}

A strong and well-built immune system is of absolute necessity for every individual. Immune physiology is strongly correlated with adequate intakes of vitamins and trace elements. ${ }^{1}$ Healthy dieting, including regular intake of vitamins and trace elements, is responsible for the immune system's proper function. Henceforth, a sufficient amount of vitamins should be present in our daily meals due to their capacity to influence and strengthen the immune system. ${ }^{2}$ A recent report demonstrated that the benefits of vitamins to the human body could not be overemphasized. Vitamin supplementation, especially vitamin D, is crucial, especially when vitamins are deficient or insufficient. ${ }^{3}$ It has been well established that high-quality nutrition is vital in modulating immune homeostasis. Any subclinical deficiency of 
micronutrients or even protein-energy malnutrition may impair one's immune responses. ${ }^{4}$

Enhancement of body innate immunity using vitamin supplements in patients suffering from viral infections has shown positive impacts. A typical example is vitamin A and D supplementation, which increases pediatric patients' humoral immunity following influenza vaccination. ${ }^{5-7} \mathrm{~A}$ review by Calder et $\mathrm{al}^{8}$ suggested that one of the primary ways to protect a person against viral infections is to maintain a well-balanced nutritional status. ${ }^{4}$ Furthermore, balanced nutrition and a varied diet have been proven to complement vitamin deficit and minimize frequent and unnecessary consumption of marketed vitamin supplements. ${ }^{9}$ A recent study by $\mathrm{Wu}$ suggested nutritional recommendations that could improve the body's immune system and significantly limit lung damage from COVID19 and other lung infections. ${ }^{10}$ In addition to proper dietary intake, lifestyle modification is necessary to prevent and treat viral diseases like the current COVID-19. To complement such efforts, regular fundamental hygienic practices should be maintained, and every individual is urged to comply with rules laid down by the government and the health authorities. ${ }^{11}$ The typical healthy eating practice encourages everybody to take a minimum of five servings of different (at least 05) fruits since one fruit is not enough to meet and combat the current global pandemic of COVID-19 situation and vegetables each day and the main meal that should contain more carbohydrates. Other components of a healthy diet include a few segments of meat or protein for vegetarians. A reasonable amount of protein-rich foods should be incorporated into daily meals. ${ }^{11}$ Unfortunately, during the lockdown period, the achievement of a well-balanced diet appeared tedious due to logistics, economic troubles, and movement restrictions, however taking a multivitamin-mineral (MVM) supplement for a limited time is very helpful, especially among the elderly populations who are more vulnerable to COVID-19 infection (Figure 1). ${ }^{12}$

Currently, malnutrition increases the burden of morbidity and mortality due to infectious diseases, which significantly affects the health care systems from an economic standpoint and the nutrition care of any country. ${ }^{13} \mathrm{~A}$ higher predisposition to morbidity and mortality caused by protein-energy malnutrition from inadequate dietary intake has been attributed to an increased rate of infections and delayed recovery, leading to a higher demand for several nutrients. ${ }^{14-18}$ Furthermore, malnourished patients or patients at risk of malnutrition are expected to take extra

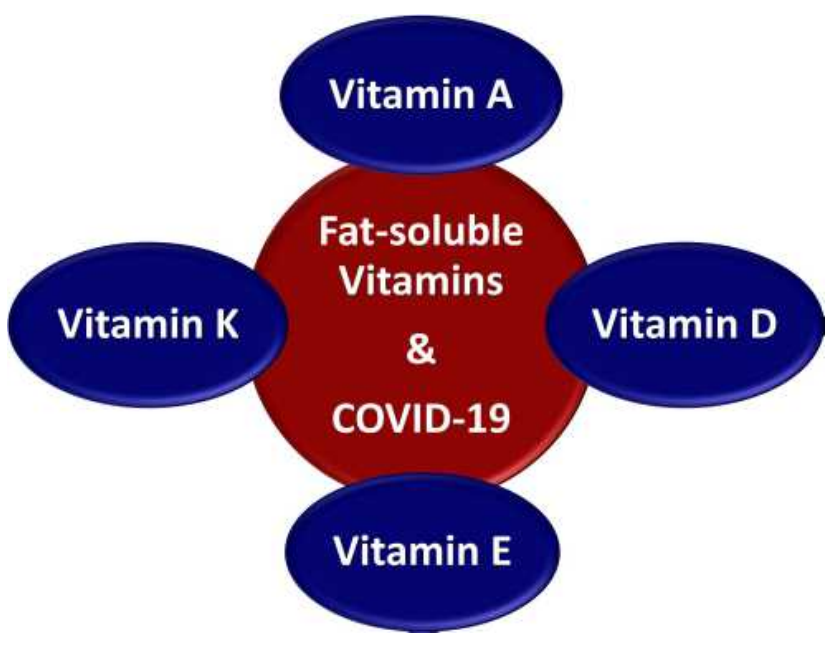

Figure I Fat-soluble vitamins crucial in COVID-19.

supplements to improve their energy, protein, and micronutrient levels. ${ }^{4}$ Notably, for a viral infection like COVID19 with minimal therapeutic approaches available for prevention and treatment, nutritional strategies for enhancing immunity remain an avenue to be explored.

Furthermore, medical nutrition therapy (MNT) performs an essential responsibility in the averting and management of malnutrition. ${ }^{19,20}$ The COVID-19 pandemic is predictable to escalate the risk of all types of malnutrition. ${ }^{21,22}$ Moreover, movement control policy, popularly known as lockdowns, messed up the overall healthcare services that deterred maternal and child health, increasing mortality. ${ }^{23,24}$ Researchers anticipated child stunting, micronutrient malnutrition, and maternal nutrition to intensify because of the disruption of national and international economies and the food supply chain. $^{25-27}$ Additionally, 3.9 million children of South Asia have a higher possibility of developing muscle-wasting. ${ }^{27}$ Thereafter, registered dietitian nutritionists (RDNs) should be motivated and energetically take the initiative to create and implement appropriate nutrition policy planning to evaluate, avert, and manage malnutrition through a multidisciplinary team-based approach for ongoing COVID-19infected patients or patients at risk. ${ }^{22,28,29}$

A most critical warning sign of the vitamin $\mathrm{C}$ deficiency ailment is known as scurvy. Scurvy has been frequently correlated with increased susceptibility to infections, predominantly of the respiratory tract, pneumonia, and pulmonary tuberculosis, and remains the primary cause of death. ${ }^{30-32} \mathrm{~A}$ classic example is the consumption of vitamin $\mathrm{C}$, which plays a prophylactic role due to its ability to facilitate the favorable immune response required for the growth and repair of body tissues. ${ }^{33}$ It 
also reduces the susceptibility of the lower respiratory tract to infections. ${ }^{34-36}$ It has been reported that patients with acute respiratory infections when receiving intravenous vitamin $\mathrm{C}$ followed by serum level increase positively correlate to minimizing the respiratory symptoms. ${ }^{37,38}$ Multiple studies reported that vitamin C possesses significant anti-inflammatory, immunomodulation, antioxidant, antithrombotic, and antiviral activities. ${ }^{39-41}$ Vitamin C positively impacts both innate and adaptive immune systems and exhibits through virucidal activity. ${ }^{33,42-45}$ Additionally, vitamin C promotes T-lymphocytes' growth and maturation process and works shoulder to shoulder in improving leukocytes physiology performance regarding the phagocytic and chemotactic process. ${ }^{33,46,47}$ Moreover, vitamin $\mathrm{C}$, with its antioxidant action, improves the phagocytic property; in this manner, it leads to increased formation of reduced vitamin $\mathrm{C}$ (ascorbic acid) from oxidized vitamin $\mathrm{C}$ (dehydroascorbic acid). ${ }^{48}$

Furthermore, vitamin $\mathrm{E}$ is a potent antioxidant and can modulate the host's immune functions. On the other hand, several studies demonstrated the harmful effects of vitamin $\mathrm{E}$ intake on the immune response. The same view has also been backed up by researchers who discouraged vitamin $\mathrm{E}$ supplementation in cardiovascular disease and cancer prevention. ${ }^{5}$ It was also speculated that a high dosage of vitamin E supplementation might increase all-cause mortality. Taken together, there is a need to investigate the prospects of these vitamins as an effective measure in the treatment of COVID-19.

\section{Objectives of the Study}

This review aims and scopes to highlight 1) role of vitamin $\mathrm{A}, \mathrm{D}, \mathrm{E}$, and $\mathrm{K}$ in COVID-19, 2) antiviral effects of vitamin $\mathrm{E}$ on COVID-19, 3) immune-boosting effects of vitamin E relevant to combat COVID-19, and 4) to conclude and give prescribers and policymakers direction.

\section{Materials and Methods}

Even though the literature investigation is an obligatory segment for systematic review and meta-analysis several critical studies about narrative review encouraged integrating a section about search strategies. In that way, this manuscript comprises the section of materials and methods. The literature search was not systematic but was based on the four core bibliographic databases (Google Scholar, PubMed, Scopus, and China National Knowledge Infrastructure). We are conscious of the specialty and strength of the web of science; nevertheless, we could not embrace it because of monetary constraints as the current paper did not obtain any fiscal support. The authors depend predominantly on open access journals and access to journals fixed by the Universiti Pertahanan Nasional Malaysia (UPNM), the National Defence University of Malaysia (UPNM), Kuala Lumpur, Malaysia, and North South University, Dhaka-1219, Bangladesh. Articles those not available in full-text or not written in English were excluded. The only non-English papers utilized refer to the historical purpose. The study was conducted between early June 2020 and mid-February 2021. The search terms used include "Coronavirus Disease 2019 Virus, Wuhan Seafood Market Pneumonia Virus, Novel Coronavirus 2019, SARS-CoV-2 Virus, COVID-19 Virus, Wuhan Coronavirus, SARS Coronavirus 2, Severe Acute Respiratory Syndrome Coronavirus 2, Vitamin A, Vitamin D, Vitamin E, Vitamin K, Trace Element, Biometals, Immune Processes, Humoral Immunity, Acquired Immunity, Adaptive Immune Response". This was trailed by the snowballing of references cited by essential manuscripts. We had included all types of peer-reviewed articles published in English. Further references were dappled through labor-intensive exploration through the selected references after the firstround search. As this paper is of a narrative nature review, both recent and older publications with historical significance were incorporated.

\section{Role of Vitamin A in COVID-19}

Vitamin A plays a vital role in metabolism and immune response. Its pleiotropic influences have been established, ranging from a diverse physiological task in maintaining the required biological need of our system, including wellknown fact in improving the eyesight. ${ }^{49}$ In recent reviews, vitamin A acts by boosting all-trans-retinoic acid (ATRA), and it is also pivotal in the maintenance of innate cellmediated and antibody-mediated responses. ${ }^{50}$ In another study on vitamin A, Field et al ascertained vitamin A's capacity to resist infection. ${ }^{51} \mathrm{~A}$ report by Mora et al proposed a decline in vitamin A uptake has a critical influence on the immune response. ${ }^{52}$ This was also further testified in the work of Cunningham-Rundles et al, who stated that HIV-infected pregnant women should be encouraged to eat food rich in vitamin A. This is because the decrease in vitamin A could predispose her to an increased risk of congenital HIV and AIDs. ${ }^{53}$ Food substances rich in vitamin A are primarily vegetables such as carrots, spinach, and sweet potato. These vegetables also constitute a group of fat-soluble compounds such as retinol, retinoic acid, and $\beta$-carotene that play a vital role in regulating immune 
responses and reducing susceptibility to infections. ${ }^{54-58}$ The mechanism adopted by vitamin A to reduce infection is often through modifying epithelial cell integrity and function, improving specific and non-specific immunity of the host, and lymphoid mass use. ${ }^{59-61}$

The three primary active forms of vitamin A include retinol, retinoic acid, and retinol. Hence, they are regarded as "anti-infectives as many of the body"s defense mechanisms against infections depend on their constant supply. Semba et al believed that adequate vitamin A supplementation helped reduce morbidity and mortality resulting from different infectious diseases. ${ }^{62}$ Examples of such conditions include diarrhea, measles, HIV infections, measles-related pneumonia, and malaria. In furtherance to this, vitamin A remains of significant importance as it offers some protection against life-threatening complications and infections such as malaria, HIV, and lung diseases. ${ }^{63-65}$ Often, they are made refractory to infection during subsequent rounds of viral replication.
Nevertheless, Jee et $\mathrm{al}^{66}$ believed that diets low in vitamin A supplements are likely to reduce inactivated bovine coronavirus vaccines' effectiveness, increasing the calves' vulnerability to infectious diseases. ${ }^{54,66,67}$ Another significant link of vitamin A to COVID-19 infection was more pronounced in its activity against the infectious bronchitis virus (IBV), a kind of coronavirus that was found more in chickens fed with a diet deficient vitamin A as opposed to those provided with adequate proportions of vitamin A. Lastly, vitamin A is envisaged to be a promising option in treating the COVID-19 pandemic by preventing lung infection (Figure 2). The method by which vitamin A and retinoids prevent measles replication is through the up-regulation of mineral elements and the innate immune response in bystander cells free of infections. ${ }^{68}$

Multiple earlier studies have reported that type 1 interferons (IFN-I) possess antiviral effects in two closely related coronaviruses, SARS-CoV and MERS-CoV, either administered single-handedly or in mish-mash with other

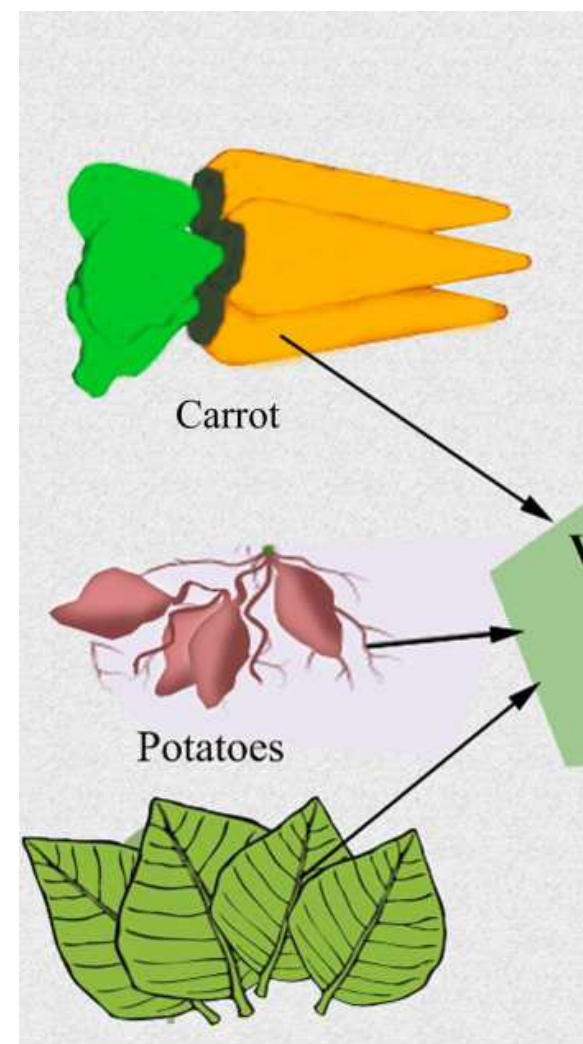

Lettuce leaves

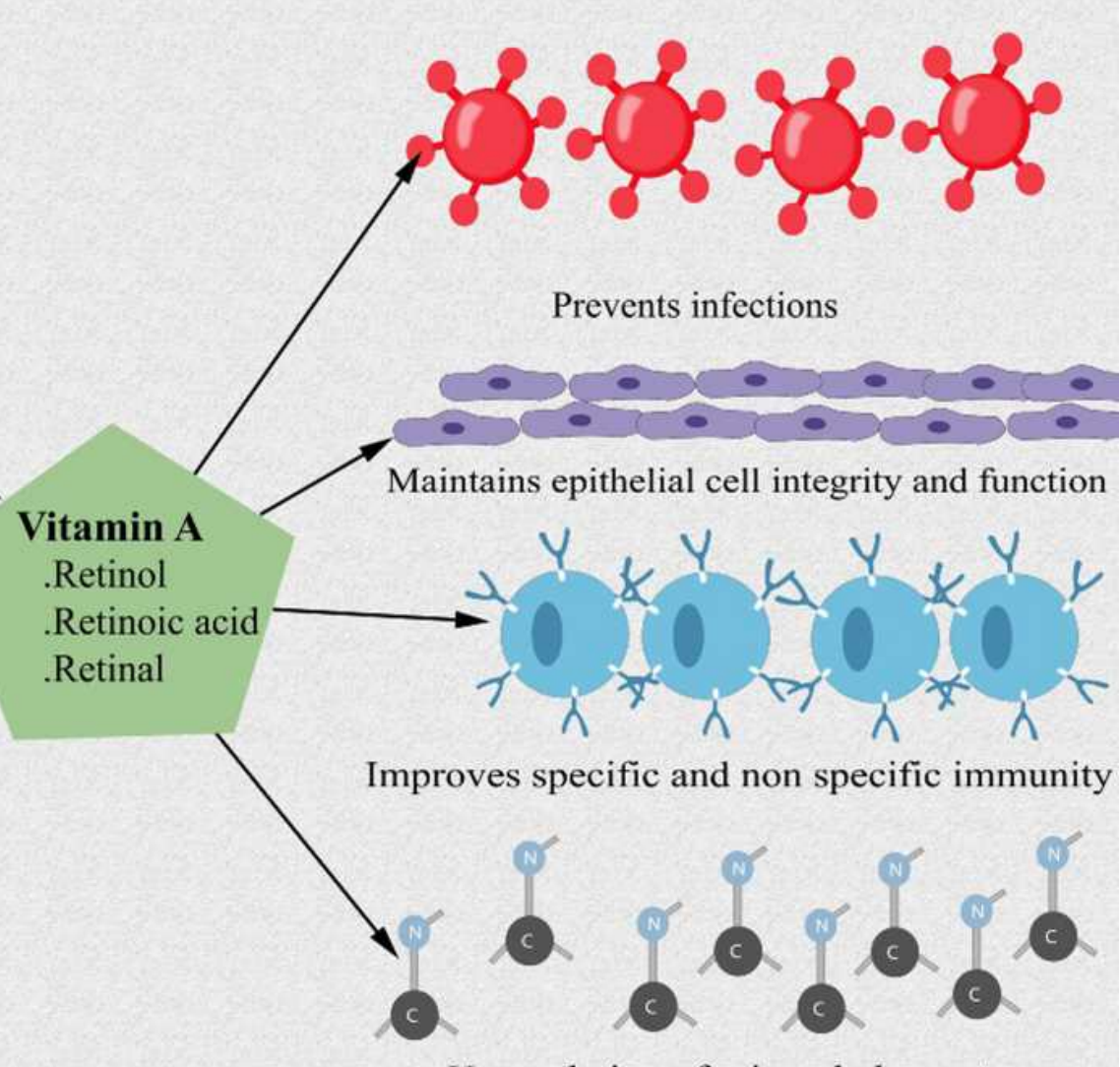

Upregulation of mineral elements

Figure 2 Role of vitamin A in COVID-19. 
antiviral medication. ${ }^{69-71}$ Additionally, retinoids are closely interconnected molecules associated with vitamin A that have robust immune-modulating chattels, together with the capability to escalate and heighten the efficacy of IFN-I. ${ }^{72,73}$ Moreover, retinoids and their related compounds have been well documented as a safe therapeutic option for over 60 years. ${ }^{74,75}$ In that way, multiple studies have reported that retinoids possess potential possibilities in the management of COVID-19. ${ }^{73,76,77}$ Recently, seven core targets of vitamin A against COVID-19 were recognized. Those are MAPK1 (mitogen-activated protein kinase 1), IL-10 (interleukin 10), EGFR (epidermal growth factor receptor), ICAM1 (intercellular adhesion molecule 1), MAPK14 (mitogen-activated protein kinase 14), CAT (catalase), and PRKCB (protein kinase C B) ${ }^{78,79}$ Thereby, several studies reported that vitamin $\mathrm{A}$ and related compounds have a potentially beneficial role in the management of COVID-19. ${ }^{77,80-82}$ Moreover, it has been reported that vitamin A can minimize COVID19-induced adverse effects on the angiotensin system and minimize medication-related adverse effects. ${ }^{83}$ On top of these novel beneficial effects, vitamin A, is well known for the positive role in promoting innate and adaptive immunity. ${ }^{2}$ By this means, vitamin A prevents or diminishes primary and secondary infections. ${ }^{84,85}$ In consequence, it improves respiratory health by curtailing inflammation and fibrosis. ${ }^{86-88}$ Furthermore, COVID-19 has been found to persuade inflammatory response/cytokine storms, especially involving liver, lung, and kidney, which further increases the risk of depletion of vitamin A stores that demand supplementation and has the prospect to restore the acceptable status and combat the grave lifethreatening disease. ${ }^{88,89}$

\section{Role of Vitamin D in COVID-I 9}

Numerous physiological, hereditary, and environmental factors account for the emerging disparity and fluctuations in the number of confirmed COVID-19 cases, morbidity, and mortality across different nations. Movement restrictions (lockdown) to reduce the exposure to COVID-19-infective cases to ensure social distancing. This measure to control COVID19 is probably one of the best instruments policymakers incorporated throughout the globe to save their countrymen. Thereafter, COVID-19 risk somewhat minimizes; nevertheless, people are less exposed to sunlight, which has enhanced vitamin D deficiency risk. Vitamin D functions in various ways, including interaction with the nonspecific defense mechanisms, activation of Toll-like receptors, and/or increment in the levels of cathelicidins and $\beta$-defensins. ${ }^{90}$ This influences the acquired immunity by lowering immunoglobulin released by plasma cells and pro-inflammatory cytokines production to modulate $\mathrm{T}$ cell function. ${ }^{90}$ Promising results further described vitamin D nutrients as an essential supplement in treating respiratory tract infections, autoimmune diseases, and pulmonary fibrosis. ${ }^{91}$ An increase in serum $25(\mathrm{OH}) \mathrm{D}$ is associated with increased beneficial bacteria and lowered pathogenic bacteria in the body. ${ }^{92}$

A classic example is that of three hospitals of Southern Asian origins that conducted a retrospective multicentre study of 212 cases with laboratory-confirmed infection of COVID-19, with a depicted data related to clinical features and serum $25(\mathrm{OH}) \mathrm{D}$ levels. ${ }^{93}$ The results suggested that an increased serum 25(OH)D level in the body could either improve clinical outcomes or mitigate severe to critical outcomes. However, a decreased serum $25(\mathrm{OH}) \mathrm{D}$ level in the body could lead to a detrimental consequence. ${ }^{93}$

The defensive effect of vitamin D against SARS-CoV-2 infection can be linked to its previous effect on other respiratory infections. ${ }^{94}$ This notion was further supported by a metaanalysis that conclusively affirmed that vitamin D intake is beneficial in acute respiratory tract infections. ${ }^{94}$ After having millions of the confirmed COVID-19 cases, evidence continually depicts the older populace and malnourished individuals as the most vulnerable groups in this disease condition. Univariate analysis in an Indonesian retrospective cohort study consisting of 780 confirmed cases of COVID-19 depicted that older patients, males sufferers with a pre-existing medical condition, and those with lower vitamin D levels were associated with an increased odds ratio of mortality. When controlling independent variables during epidemiology such as age, sex, and comorbidity, low vitamin D status is strongly associated with increasing cases of COVID-19 mortality. ${ }^{95}$ Seneca et al demonstrated that older people have an average serum vitamin D level of $26 \mathrm{nmol} / \mathrm{L}$ in Spain, $28 \mathrm{nmol} / \mathrm{L}$ in Italy, and $45 \mathrm{nmol} / \mathrm{L}$ in the Nordic countries. In Switzerland, the intermediate vitamin $\mathrm{D}$ level is $23 \mathrm{nmol} / \mathrm{L}$ in nursing homes; and data from Italy indicated that $76 \%$ of women over 70 years of age have vitamin D levels below $30 \mathrm{nmol} /$ L. ${ }^{96}$ These estimates of low vitamin D levels among the elderly across Europe showed that the aging population represents the group with the highest risk of morbidity and mortality with SARS-CoV-2 infection. ${ }^{97}$

The recommended dietary allowances (RDA) for Vitamin $\mathrm{D}$ are $10 \mu \mathrm{g} / \mathrm{day}$ and $15-20 \mu \mathrm{g} / \mathrm{day}$ for infants and adults, respectively. Additionally, the sources to supply Vitamin D 
accounts for a limited number of nutritional sources such as cod liver oil, catfish, mushrooms, etc. The content of most of the milk supplies in the US is added with 400 IU vitamin D per quart, and the same applies to the vegetative alternatives (soy milk, almond milk, oat milk, etc.). ${ }^{98}$ Currently, the majority of breakfast, including bowls of cereal and some orange juice brands, yogurt, margarine, and soy beverages, are fortified with vitamin $\mathrm{D}$. This vitamin is usually added in two different forms that are vitamin D2 (ergocalciferol) and D3 (cholecalciferol) that collectively increase vitamin $\mathrm{D}$ in the blood. ${ }^{99}$ Based on previous studies, patients with respiratory disease, to rapid and safe increase serum $25(\mathrm{OH}) \mathrm{D}$ levels, and patients with low circulating levels (below $50 \mathrm{nmol} / \mathrm{L}$ ) can be offered vitamin D supplementation of 50,000 IU twice a week. ${ }^{100,101}$ Overall, doses above $6000 \mathrm{IU} / \mathrm{d}$ are needed to achieve serum $25(\mathrm{OH}) \mathrm{D}$ concentrations above $100 \mathrm{nmol} / \mathrm{L}$, and intakes of vitamin D up to $15,000 \mathrm{IU} / \mathrm{d}$ (Figure 3) were found to be safe. $^{101,102}$

The effectiveness of vitamin $\mathrm{D}$ in reducing infections that may require hospitalization cannot be overemphasized, especially with the rising incidences of COVID-19. Consequently, frontline warriors working in hospitals treating COVID-19 patients linked with increased risk of COVID-19 infection require vitamin $\mathrm{D}$ supplementation. This was further justified by a report in which 40 out of 138 admitted COVID19 cases in Wuhan in the Zhongnan Hospital from 1 to 28 January were healthcare workers. ${ }^{103}$ It was announced that COVID-19 infected more than 1700 Chinese health workers, out of which 6 already died by 14 February 2020. ${ }^{104}$ Another study revealed that 152,888 confirmed cases and 1413 deaths among healthcare workers around the globe. ${ }^{105}$ Medscape reported on 11 March 2021, that over 3000 healthcare workers passed away in the last year because of COVID-19. ${ }^{106}$ Aljazeera reported on 5 March 2021 that according to Amnesty International, at least 17,000 health workers have died globally from the current global pandemic COVID-19. ${ }^{107}$ A dose of at least $40-50 \mathrm{ng} / \mathrm{mL}(100-125 \mathrm{nmol} / \mathrm{L})$ of vitamin $\mathrm{D}$ is recommended for individuals as prophylaxis based on observational studies. ${ }^{108-111}$ During the COVID-19 pandemic, it is crucial that all people in the hospital, including the patients

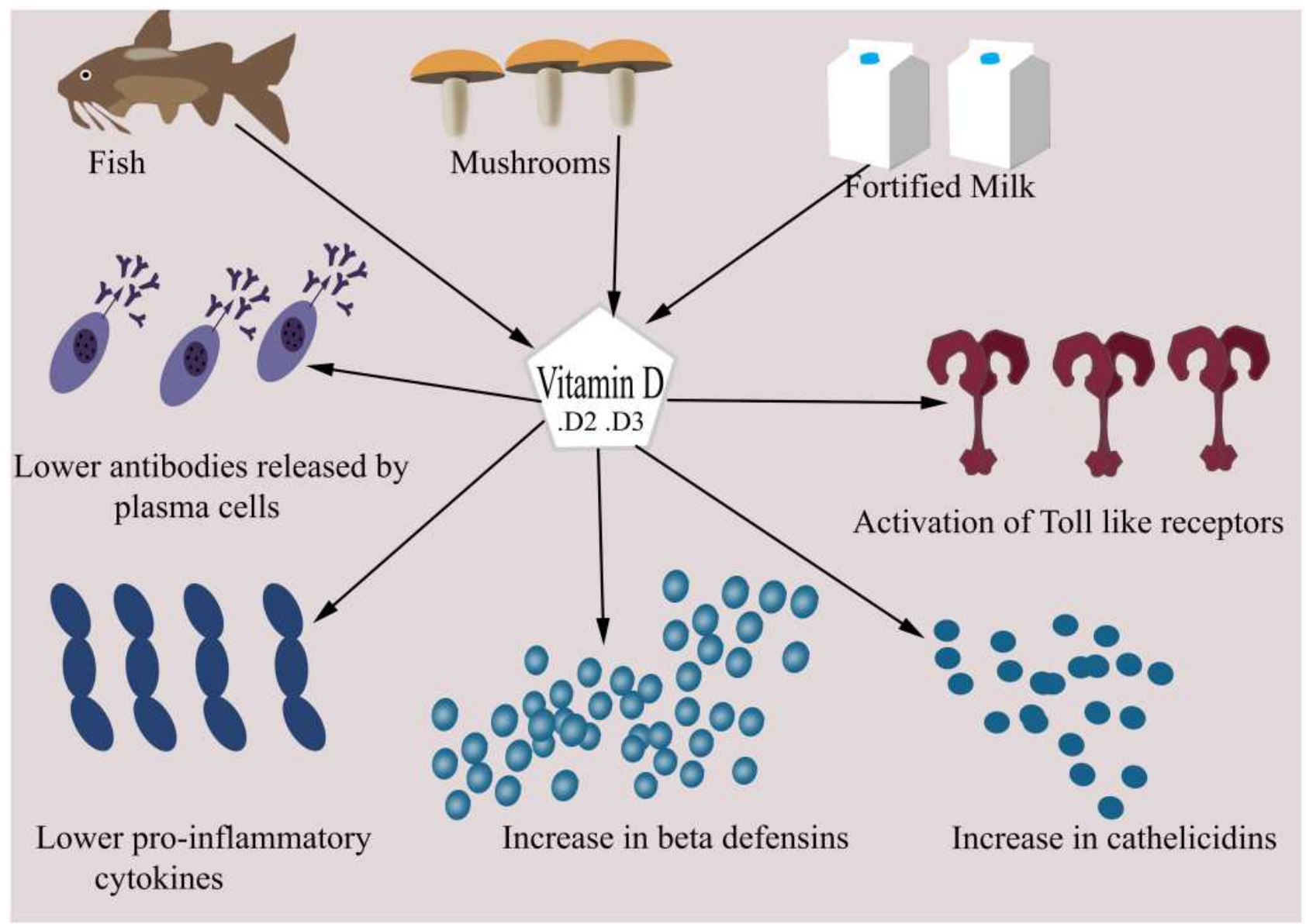

Figure 3 Role of vitamin D in COVID-19. 
and staff, take vitamin D supplements to raise $25(\mathrm{OH}) \mathrm{D}$ concentrations as an essential step in preventing infection spread. $^{112}$

Before recommending vitamin D to a particular population, initial testing of their vitamin $\mathrm{D}$ level at an interval is advocated to determine the dosing levels required. Moreover, there should be followed up to determine whether vitamin $\mathrm{D}$ is adequate until vitamin $\mathrm{D}$ status is optimal. This is important because once vitamin D deficiency is corrected, giving more vitamin D supplementation may not provide additional benefits. ${ }^{113}$ The dosing should be done continuously, even without the occurrence of respiratory tract infection. Amid this pandemic, there is difficulty in routine maintenance of vitamin D supplements ranging from its preparation to storage, distribution, and quality control. ${ }^{109,114}$ With proper blinding, randomized controlled trials with a higher number of subjects from representative populations should be conducted to evaluate these recommendations.

\section{Role of Vitamin E in COVID- 9} Antiviral Effects of Vitamin E on COVID-19 Coronaviruses are a family of common RNA viruses. They are potential causes of severe lower respiratory tract infections, followed by pneumonia, which is generally associated with cytokine storm production, inflammation, cell death, and other pathophysiological processes involving redox imbalance or oxidative stress. ${ }^{115}$ COVID-19 patients are at a higher risk of developing inflammatory responses associated with fatal respiratory distress. Although limited clinical data is available to establish a link between oxidative stress and viral infection due to SARS-CoV-2, many lines of evidence still suggested that overproduction of reactive oxygen species (ROS) and deprived antioxidant system play a significant role in the pathogenesis and severity of SARS-CoV-2 viral infection. ${ }^{116}$ Reactive oxygen and nitrogen species (RONS) and other free radicals resulting from oxidative stress are potential causes of cell membrane damage by lipid peroxidation, oxidation, and protein denaturation. According to a few studies, it is often suggested that the onset of severe lung injury in COVID19 patients is based on the activation of the oxidative stress mechanism coupled with an innate immune response that activates the transcription factor NF-kB resulting in an exacerbated pro-inflammatory host response associated with the pathophysiology of the virus. ${ }^{116-120}$ In like manner, another study suggests an upregulation of mitochondrial genes and genes responding to oxidative stress in peripheral blood mononuclear cells (PBMC) of convalescent SARS-CoV-2 patients. Stress response protein DNAJB1, differentiation-associated gene IFRD1, cytokine IL-1B, and other genes were overexpressed in the PBMC of these patients. These results support the association between oxidative stress, inflammation, and pathogenesis of SARS-CoV-2 infection. ${ }^{121}$

Vitamin $\mathrm{E}$ is a fat-soluble antioxidant that can protect the polyunsaturated fatty acids (PUFAs) in a membrane from oxidation, regulate RONS production, and modulate signal transduction. ${ }^{122}$ It facilitates the inhibition of protein kinase $\mathrm{C}$ activity by enhancing PKC-alpha dephosphorylation via activation of protein phosphatase $2 \mathrm{~A}$ by vitamin $\mathrm{E}$ has been demonstrated in different cells, and the suppression of platelet aggregation, reduced proliferation of macrophages, and decreased superoxide production in neutrophils and macrophages. ${ }^{123}$ The high concentration of vitamin $\mathrm{E}$ present in immune cells of COVID-19 patients defends them from oxidative damage because of its high metabolic activity and PUFA contents in ageassociated dysregulation of the immune system. ${ }^{124-129}$ Vitamin E donates hydrogen to reactive free radicals, becomes oxidized, and quenches the reactive species produced from oxidative stresses. ${ }^{130-132}$ Vitamin E antioxidant therapeutic potential can be exploited to prevent oxidative damages associated with the SARS-CoV-2 pathogenesis due to its scavenging effects. ${ }^{133-135}$

\section{Immune-Boosting Effects of Vitamin E That Can Help Combat COVID-19}

The novel coronavirus pandemic has affected millions of people all over the world. SARS-CoV-2 enters the cell via the viral trimeric spike protein binding with the host's angiotensin-converting enzyme-2 (ACE2) receptor and mainly affects the lower respiratory tract. It also binds to ACE2 on the alveolar epithelial cells after infecting the human body. ${ }^{136}$ Immediately after binding, it creates a successive immune response through inflammation-related manifestations and recruitment of antigen-presenting cells (APC), which results in an infection of innate and adaptive immunity within the cells. ${ }^{137-139}$ SARSCoV-2 inhibits the rapid expression of interferon type-1 (IFN1), which is known as "initial alarm." "140 IFN-1, upon encounter with the virus, influences the immune cells to the "antiviral state." 140

Consequently, the compromised function of IFN-1 would favor immune evasion. On the other hand, antigen 
presentation via $\mathrm{MHC}$ class $1 / 2$ may be compromised by infected APC, leading to an impaired T-cell response. ${ }^{141} \mathrm{~T}$ helper cells produce proinflammatory cytokines and chemokines, which in turn recruit lymphocytes, monocytes, and neutrophils, followed by the secretion of vast amounts of cytokines from all these immune cells, an increase in the inflammatory processes. This uncontrolled and massive release of proinflammatory cytokines such as IL-6 and tumor necrosis factor (TNF-alpha) is termed the "cytokine storm," leading to T-cell suppression. ${ }^{142}$

Vitamin E, a fat-soluble natural antioxidant, has very little evidence of antiviral actions; instead, it reduces inflammatory cytokine production and improves $\mathrm{T}$ cell proliferation by directly impacting membrane integrity, signal transduction, and $\mathrm{T}$ cell differentiation. Vitamin $\mathrm{E}$ supplementation enhances leukocyte phagocytic activity and functions of neutrophils and natural killer (NK) cells. ${ }^{143}$ Vitamin $\mathrm{E}$ is known to affect inflammatory responses in different tissues, including the lungs, via direct scavenging oxidative stress and modulation of oxidative eicosanoid pathways and prostaglandin synthesis; it also influences inhibition of inflammatory mediators and control of apoptotic lipid signaling. ${ }^{144}$ Different cell-based animal and human studies have shown evidence of the mechanism involved in vitamin E's immunomodulatory effects of vitamin E. These studies have demonstrated that vitamin $\mathrm{E}$ has direct and indirect effects on immune cells, especially on the $\mathrm{T}$ cells. ${ }^{145}$ The immunoregulatory function of vitamin $\mathrm{E}$ has clinical relevance as it affects a host's susceptibility to viral infection, thereby reducing the risk of respiratory diseases. ${ }^{3,146}$ In the absence of any known effective treatment for COVID-19, nutrients and food supplements that exert anti-inflammatory and immunomodulatory effects can lay significant protective function. In this light, uptake of vitamin $\mathrm{E}$ as a nutrient can be categorized as a vital prospect in treating the SARS-CoV-2 virus (Figure 4).

\section{Preliminary Results of Vitamin E Treatment in COVID-19}

Investigations of antioxidant vitamins' effectiveness, especially vitamin $\mathrm{E}$, are still ongoing as a potential treatment for COVID-19 patients. Nevertheless, several studies showed immunoregulatory functions and preventive functions from the oxidative disruption caused by vitamin E. This act has contributed to its recognition as potential agents while treating patients infected with COVID-19. Vitamin E, vitamin C, and selenium have been demonstrated in various studies to have beneficial effects that reduce oxidative stress in patients with this

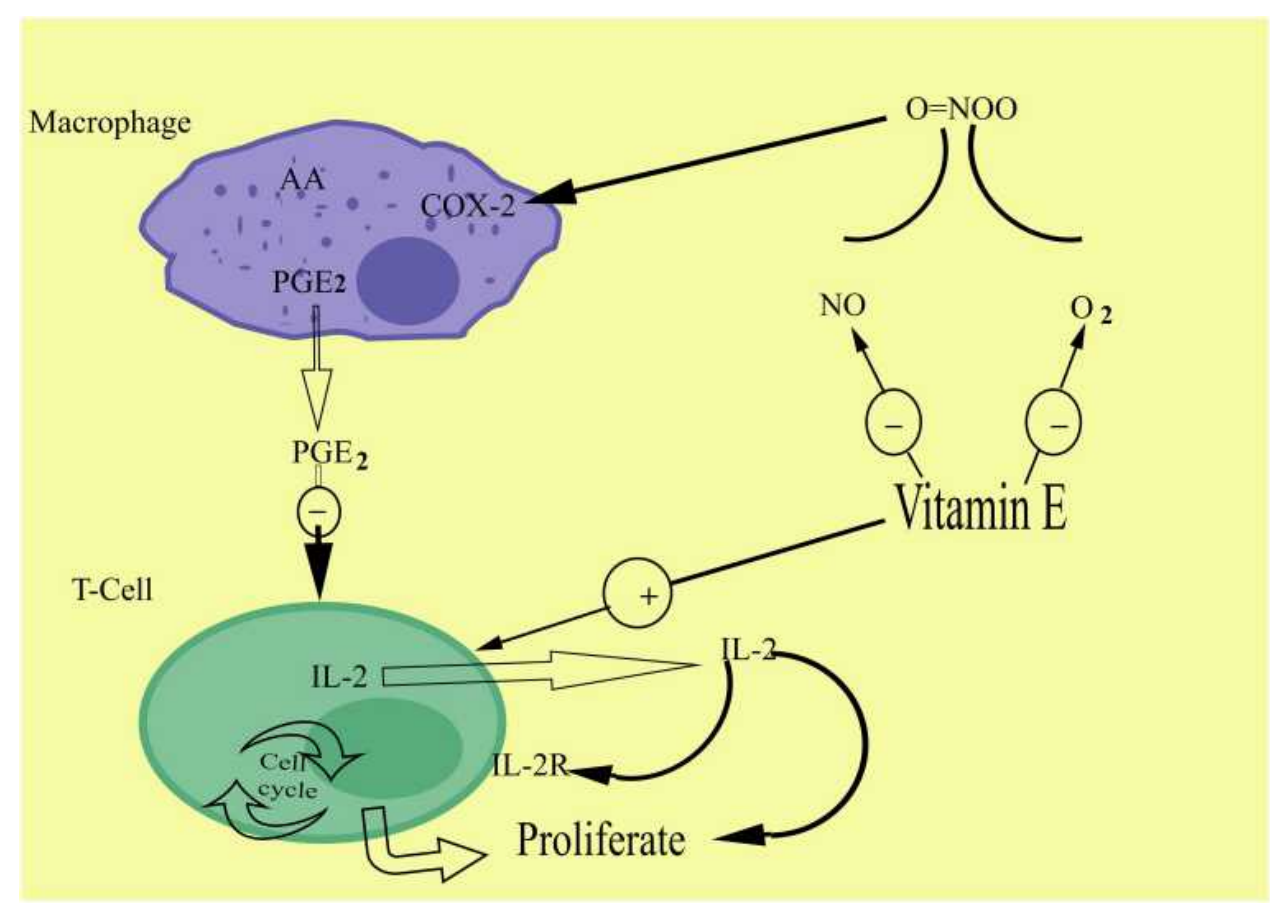

Figure 4 The immunomodulatory function of antioxidant vitamin E. 
infection $^{147}$ including COVID-19. ${ }^{35,148-150}$ Despite its possible prospects, a lot still needs to be considered as the use of this nutrient will require a long route in its achievement as a successful therapeutic measure for COVID-19 patients.

\section{Prospects of Vitamin E as Adjuvant Therapy in COVID-19}

Researchers have often claimed that the effect of COVID19 infection is particularly detrimental to the health of vulnerable populations such as the elderly and pregnant women. ${ }^{151-156}$ Older people with severe diabetes, cardiovascular diseases, cancer, etc., are predisposed to COVID19 infection due to immunosenescence. ${ }^{157-159}$ Vitamin E administration among elderly patients is likely to help the immune function, which increases the chances of infection resistance and decreases mortality that could be triggered by infection. ${ }^{160-163}$ Multiple studies regarding vitamin E's potential benefits to COVID-19 patients indicated that vitamin $\mathrm{E}$ and $\mathrm{C}$ in combination could be a beneficial antioxidant therapy for cardiac implications of COVID19. ${ }^{1,164-168}$ Despite these facts, there is limited evidence that suggests the use of vitamin $\mathrm{E}$ as adjuvant therapy for COVID-19. ${ }^{145,169}$

\section{Sources of Vitamin E}

Numerous food sources provide vitamin E, such as nuts, seeds, and vegetable oils, a vital alpha-tocopherol source with significant amounts in green leafy vegetables and fortified cereals. Other selected food sources include wheat germ oil, sunflower seeds, dry roasted almonds, sunflower and safflower oils, hazelnuts, peanut butter, corn oil, spinach, broccoli, kiwi fruit, mango, yams, sweet potatoes, soybean oil, etc. ${ }^{170}$

\section{Daily Recommended Dose of Vitamin E in COVID-19 Patients}

Even though vitamin $\mathrm{E}$ is a potential beneficial nutrient against COVID-19, there is no recommended dosage estimate. However, the recommended daily intake of vitamin E is $15 \mathrm{mg}$ per day for healthy individuals. ${ }^{171}$

\section{Future Needs for Vitamin E and Its Limitations}

Concerning the limited evidence available on vitamin $\mathrm{E}$ prospects, scientists are investigating whether, by free radical scavenging mechanisms, immune function, or other possible potential effects of vitamin E, they can prevent or delay the severity of the SARS-CoV-2 virus and its associated complications. ${ }^{77,172}$ Vitamin E supplements more than RDA showed no additional impact; instead, studies reported that very high intake might cause several body complications. ${ }^{173}$ Moreover, a significant vitamin E limitation can be recommended for their antioxidant actions and immunoprotective functions. ${ }^{147}$ However, there is still little progress in using them as therapeutic agents for chronic diseases and severely ill patients.

\section{Role of Vitamin K in COVID- 19}

Vitamin $\mathrm{K}$, one of the fat-soluble vitamins, is essential for synthesizing several proteins - factor II (prothrombin), factors VII, IX, and X involved in regulating blood clotting (coagulation). ${ }^{174}$ Natural vitamin $\mathrm{K}$ is found in two different forms: K1 (phylloquinone), an effective form of dietary vitamin $\mathrm{K}$ and mainly found in green leafy vegetables, and K2 (menaquinones). ${ }^{175}$ They are primarily of microbial origin, and sources are especially from fermented foods like cheese, curds, and animal livers. It is noteworthy to understand that these menaquinones are synthesized by human intestinal microbiota. ${ }^{176-178}$ The third form of vita$\min \mathrm{K}$ is $\mathrm{K} 3$ (menadione), which is synthetically or artificially produced. ${ }^{179}$ The dietary reference intake of vitamin $\mathrm{K}$ recommended by Food and Nutrition Board (FNB) at the Institute of Medicine of the National Academies is $120 \mathrm{mcg}$ for adult males and $90 \mathrm{mcg}$ for adult females. ${ }^{180}$ Research has revealed the role of vitamin $\mathrm{K}$ beyond blood coagulation. ${ }^{181}$ Vitamin K's consumption, combined with anticoagulant drugs such as warfarin, can threaten individuals who take them. Vitamin K and vitamin K-dependent proteins are vital for calcification (maintaining bone and cardiovascular health), energy metabolism, and inflammation. ${ }^{175,181}$ To lower the risk of vascular deformation, an adequate intake of vitamin $\mathrm{K} 2$ is found to be effective. This is because it activates matrix Gla protein (MGP), inhibiting calcium deposition in the vessel walls. ${ }^{182}$ Another importance of this vitamin $\mathrm{K}$ is its ability to act as a potent antioxidant reducing the lipid peroxidation in the cell by producing vitamin $\mathrm{K}$-hydroquinone, a robust radical scavenging species. ${ }^{183,184}$ Vitamin $\mathrm{K}$ has been found to have an anti-inflammatory activity, which would probably modulate through NF-KB signaling [Figure 5]. ${ }^{185}$

Typically, the risks for vitamin $\mathrm{K}$ deficiency in adults include high consumption of vitamin $\mathrm{K}$ antagonists like warfarin (which blocks the vitamin K-dependent pathway, 


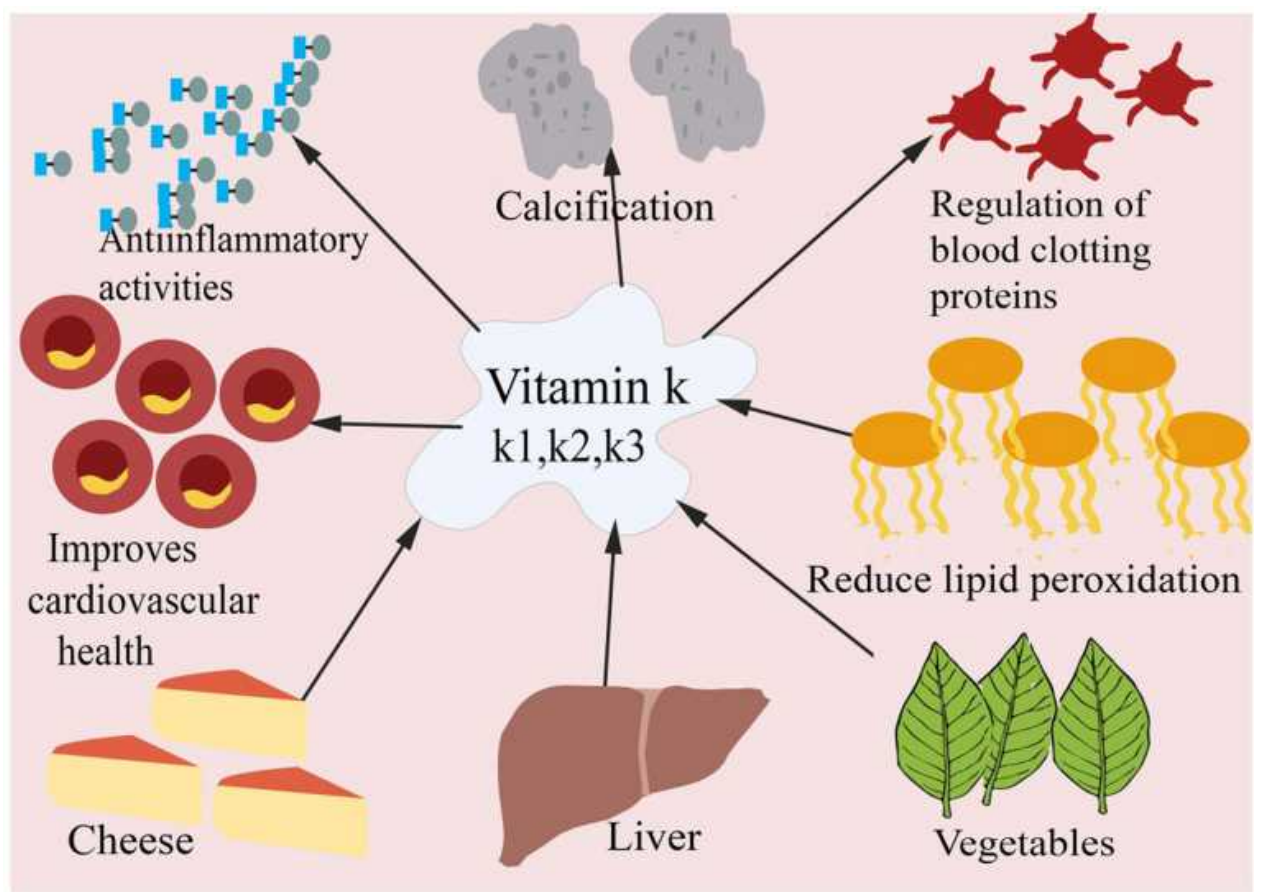

Figure 5 Role of vitamin $\mathrm{K}$ in maintaining health.

reducing the body's ability to produce blood-clotting proteins) and individuals with liver diseases and disorders. ${ }^{186}$ Mothers who are on anticonvulsant medications (to prevent seizure) could act as a risk factor for infants and can lead to a bleeding disorder known as vitamin $\mathrm{K}$ deficiency bleeding (VKDB) of the newborn. ${ }^{187}$ Excessive intakes of $\mathrm{K} 1$ and $\mathrm{K} 2$ forms of vitamin $\mathrm{K}$ are not related to abnormal coagulation, and no known associated toxicity has been reported yet. ${ }^{188,189}$ Nevertheless, in Menadione's case, it can interfere with glutathione activity (antioxidant), resulting in oxidative damage to the cell membrane. Menadione has also been reported to induce hepatic toxicity, jaundice, and hemolytic anemia. ${ }^{188,189}$

Consequently, menadione is no longer suggested for vitamin $\mathrm{K}$ deficiency treatment. ${ }^{186}$ Vitamin $\mathrm{K}$ deficiency can contribute to excessive bleeding, poor bone development, increased risk of osteoporosis and fractures, as well as several cardiovascular diseases involving vascular calcification and atherosclerotic plaques. ${ }^{179,190}$ Reduced vitamin K levels have also been reported in COVID-19 patients. ${ }^{191}$ Several factors may contribute decreased dietary intake, ${ }^{192}$ high alcohol consumption, ${ }^{193}$ and excessive use of medications containing anticoagulants like warfarin ${ }^{194}$ during the lockdown.

Recently researchers observed the link between individuals with vitamin $\mathrm{K}$ status and COVID-19 outcomes. Coagulopathy is one of the primary features of poor outcomes in patients who develop sepsis from an infection. Similarly, coagulopathy has been observed in severe COVID-19 patients and is associated with poor prognosis, as observed by Tang et al in 183 consecutive patients. ${ }^{195}$ One of the most common laboratory findings in COVID-19 patients is the elevation of Ddimers. ${ }^{196}$ Coagulopathy and disseminated intravascular coagulation (DIC) appear to be associated with high mortality rates. Among the parameters, the D-dimer peak was a strong predictor of COVID-19 mortality. ${ }^{197}$ The other laboratory markers recommended by the International Society of Thrombosis and Hemostasis (ISTH) for monitoring DIC formation are fibrinogen, prothrombin time, and platelet count. ${ }^{198}$

Patients in the Intensive Care Unit (ICU) are at risk of vitamin $\mathrm{K}$ deficiency with elevated $\mathrm{D}$-dimer protein levels. This deficiency reduces the functional levels of coagulation factors II, VII, IX, and X, predisposing them to develop coagulopathy, increasing hemorrhage risk, ${ }^{199,200}$ and DIC formation. DIC is well recognized for its function in contributing to multi-organ system failure due to the accumulation of thrombus in the microvasculature. ${ }^{201}$ (86). Also, low vitamin $\mathrm{K}$ level appears to be associated with increased elastin degradation, ${ }^{191,202}$ preferably degrading the lung tissue, resulting in breathing difficulty in COVID-19 patients. Since COVID-19 patients with severe disease are associated with co-morbidities such as cardiovascular diseases, type II diabetes, or hypertension, which are linked to reduced vitamin $\mathrm{K}$ 


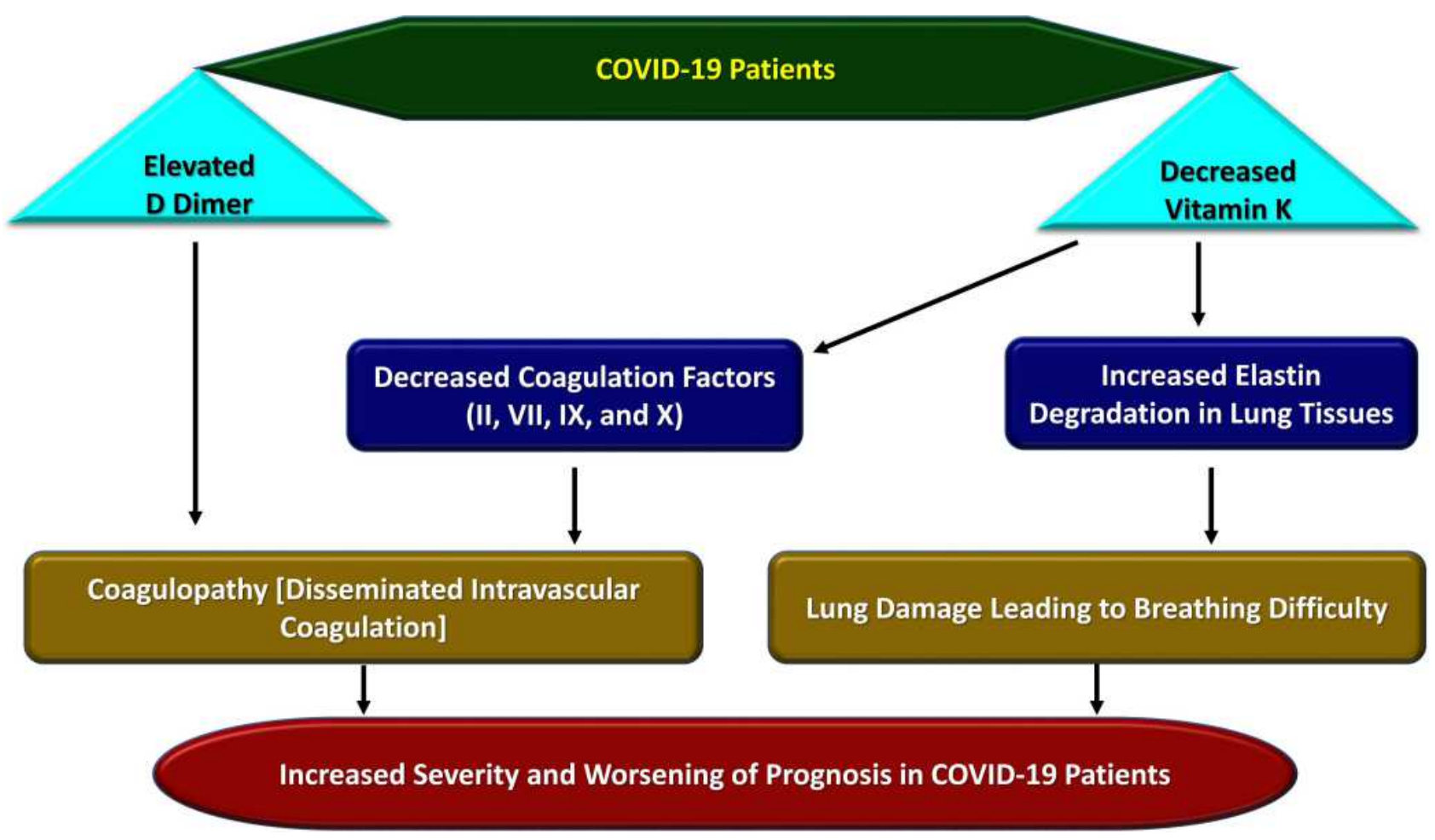

Figure 6 Importance of vitamin K in COVID-19 patients.

levels, it is hypothesized that low vitamin $\mathrm{K}$ levels might be associated with severity in COVID-19. ${ }^{203-205}$ Furthermore, a study conducted by Dofferhoff et al measuring the level of desphospho-uncarboxylated matrix Gla protein (DP-ucMGP, inversely related to vitamin $\mathrm{K}$ status) and comparing between 123 COVID-19 patients and 184 controls concluded that reduction of vitamin $\mathrm{K}$ levels in COVID-19 patients than the controls and is related to poor prognosis (Figure 6). ${ }^{191}$

For the treatment of COVID-19 induced coagulopathy, the use of an anticoagulant is recommended. A study concluded that the use of unfractionated heparin (UFH) might be a better choice of anticoagulant for treating coagulopathy in COVID-19 patients when compared to low molecular weight heparin (LMWH). ${ }^{198}$ However, the correct dose needs to be established. Simultaneously, the use of recombinant activated factor VIIa (rVIIa) is not recommended for COVID-19 patients. $^{206}$ Likewise, Thachil et $\mathrm{al}^{207}$ suggested the need to switch the patient receiving vitamin $\mathrm{K}$ antagonist (VKA) to direct oral anticoagulants (DOAC) for coagulation therapy to reduce laboratory testing frequency monitoring during this pandemic.

Nevertheless, it is not applicable for patients with mechanical heart valves or anti-phospholipid syndrome. ${ }^{207}$ Since there is a risk of vitamin $\mathrm{K}$ deficiency in patients admitted to ICU, administering vitamin $\mathrm{K}$ supplements to patients during admission to ICU might help reduce the risk of vitamin $\mathrm{K}$ deficiency and further complications. ${ }^{200}$ However, other studies are still needed to verify the results. Notably, the prescription of anti-vitamin $\mathrm{K}$ anticoagulants is not recommended for pregnant or lactating women. It may place the newborn at an increased risk of vitamin $\mathrm{K}$ deficiency. ${ }^{208}$

Furthermore, prolonged use of broad-spectrum antibiotics like cephalosporins can interfere with vitamin $\mathrm{K}$ synthesis by intestinal flora and lower vitamin $\mathrm{K}$ absorption level by altering gastrointestinal functioning, which should be considered during the infection.209 These studies illustrate that poor vitamin $\mathrm{K}$ status is linked to poor prognosis and worse outcomes. Thus, maintained vitamin $\mathrm{K} 2$ level is essential for better health, including cardiovascular, bone, and lung health. However, further studies are required to assess whether vitamin $\mathrm{K}$ administration improves the severity of COVID-19 patients.

\section{Limitations of the Study}

1. Hence, the study is a narrative review that does not follow the PRISMA methodology for Preferred 
Reporting Items for Systematic Reviews and Metaanalyses, Protocols 2015 (PRISMA-P 2015).

2. There are limited data from randomized, doubleblind controlled clinical trials to support the efficacy of fat-soluble vitamins in managing COVID-19 infection.

3. Pre-print publications were also used during the review because research in COVID-19 disease is novel and incessantly developing field of study.

4. Also, we did not authenticate the quality of the articles used in this study using scales such as the Newcastle-Ottawa scale due to the presence of preprint articles.

5. The research has no supporting fund to enable the purchase of articles that are not open to access.

\section{Conclusion}

The big data presented by various previous studies depict the efficacy of fat-soluble vitamins such as vitamin A, D, $\mathrm{E}$, and $\mathrm{K}$ in immune-modulation and lowering the severity of disease in patients with COVID-19 infection. These vitamins are pivotal in the maintenance and modulation of innate and cell-mediated, and antibody-mediated immune responses. The fat-soluble vitamins are functional in various ways, including increasing the levels of cathelicidins and $\beta$-defensins, regulating RONS production, and influencing the acquired immune system by reducing immunoglobulin secretion by plasma cells and pro-inflammatory cytokines production to modulate $\mathrm{T}$ cells function, etc. Vitamin A, D, E, and $\mathrm{K}$ boost the body's defense mechanism against COVID-19 infection and specifically prevent its complications such as cytokine storm and other inflammatory processes, leading to increased morbidity and mortality overemphasis. However, more detailed randomized double-blind clinical pieces of evidence are required to define the use of these supplements in preventing or reducing the severity of the COVID-19 infection.

\section{Recommendations}

Based on the supportive evidence, it is crucial to take vitamins like vitamin $\mathrm{A}, \mathrm{D}, \mathrm{E}$, and $\mathrm{K}$ in recommended portion to maintain a healthy immune system and physiology. Future studies are highly advocated to determine pharmacokinetics and pharmacodynamics with adverse drug reaction profile and cost. Apart from these fat-soluble vitamins, other micronutrients and minerals are also essential in maintaining adequate immunity. Eating vegetables and fruits containing the above vitamins daily is recommended to maintain a balanced diet. Supplementation of vitamin D can prove a crucial step to help prevent a worse prognosis in COVID-19.

\section{Article Highlights}

- Micronutrients and vitamins are crucial in maintaining the normal health of an individual.

- Fat-soluble vitamins like vitamin A, D, E, and K have shown some promise in the therapy of COVID-19.

- Vitamin A, with its immunomodulation effects and maintaining epithelial integrity, can prove crucial in SARS-CoV-2 infection.

- Many trials and retrospective studies have supported evidence of the usefulness of vitamin D in COVID19 patients.

- Vitamin E acts as an immunomodulator and reduces the reactive oxygen species, which help minimize the inflammation-induced damage, yet appropriate dosage and usefulness in COVID-19 are yet to be decided.

- Vitamin K deficiency is associated with various diseases, increasing the severity and mortality in COVID-19 patients with associated co-morbidities.

\section{Professional Annotation}

In the light of limited therapeutic strategies for the treatment of viral diseases like COVID-19, research suggests that the exploration of nutritional standards capable of enhancing immune system function at this time is of very high value. Considering this fact, authors have held that a healthy immune system and its ability to function correctly are critical assets for any individual. It is undoubtedly linked to the uptake of several vitamins and trace elements. ${ }^{1,2}$ The importance of adequate nutrition remains vital in regulating the body's homeostasis as any sub-clinical deficiency of even a micronutrient could disrupt normal immune functions. ${ }^{4}$ In support of this view, vitamin supplementations and well-balanced diets have been recognized to influence immune system functions, particularly in viral infections positively. ${ }^{4-7}$ In preventing and treating respiratory viral diseases like COVID-19 cases, proper dietary intake, healthy lifestyle changes, and maintaining acceptable hygienic practices are unique requirements. However, there are difficulties in obtaining a well-balanced diet in many nations due to the various restriction measures set out to curb this virus. 
Notwithstanding this, the uptake of multivitaminmineral (MVM) supplements in the meantime have been found helpful, particularly for the vulnerable groups. ${ }^{12}$ Conversely, malnutrition poses a substantial threat to healthcare systems as it increases mortality and morbidity in many nations across the globe. ${ }^{13}$ A possible explanation for this trend has been linked to a higher rate of infectious transmission and delayed recovery, which in no small measure leads to demand for several nutrients. ${ }^{14}$

On a positive note, various vitamins remain beneficial in alleviating viral infections and other respiratory conditions. A classic example is vitamin A, a promising option in treating the COVID-19 pandemic and preventing lung infection. It plays a vital role in body metabolism, regulating immune responses from minute details like the eyesight to functional body organs and reducing diseases' susceptibility. ${ }^{49,54}$ In support of its role, Semba et $\mathrm{al}^{62}$ stated that an adequate uptake of vitamin A supplements reduces morbidity and mortality resulting from infectious diseases such as diarrhea, measles, HIV infections, measles-related pneumonia malaria. Taking a glance at vitamin $\mathrm{D}$, it can be suggested that numerous physiological, hereditary, and environmental factors account for the emerging disparity and fluctuations in the number of confirmed SARS COVID-19 cases and mortality rates globally. This is exemplary in movement restrictions to reduce the exposure of many individuals to COVID-19, which has enhanced their risk of being deficient in vitamin $D$. Promising results have extensively described vitamin D nutrients as an essential supplement in treating respiratory tract infections, autoimmune diseases, and even pulmonary fibrosis. ${ }^{91}$ Next in this category is vitamin E, a beneficial antioxidant therapy in oxidative damages associated with the SARS-CoV-2 virus's viral pathogenesis due to its scavenging effects. Researchers have opined that the impact of COVID-19 is particularly detrimental to the health of vulnerable populations such as the elderly, pregnant women, and children. Older people with severe diabetes, cardiovascular diseases, cancer, etc., are even more susceptible to COVID-19 infection. The uptake of vitamin E by these patients is likely to help the immune function, which increases their chances of infection resistance and decreases mortality that could be triggered by infection. Nevertheless, several studies showed immunoregulatory functions and preventive functions from the oxidative disruption caused by vitamin $\mathrm{E}$. This act has contributed to its recognition as potential agents while treating patients infected with COVID-19. The immunoregulatory process of vitamin $\mathrm{E}$ has clinical relevance as it affects a host's susceptibility to viral infection, thereby reducing the risk of respiratory infections. ${ }^{146}$ Multiple studies regarding the potential benefits of vitamin E to COVID-19 patients indicated that vitamin $\mathrm{E}$ and $\mathrm{C}$ in combination could be a beneficial antioxidant therapy for cardiac implications of COVID-19. ${ }^{1,164-166}$ In the absence of any known effective treatment for COVID-19, nutrients and food supplements that exert anti-inflammatory and immunomodulatory effects can lay significant protective function.

Despite its possible prospects, a lot still needs to be considered as the use of this nutrient will require a long route in its achievement as a successful therapeutic measure for COVID-19 patients. Recently, researchers started to observe the link between individuals with vitamin $\mathrm{K}$ status and COVID-19 outcomes. Coagulopathy is one of the primary features of poor outcomes in patients who develop sepsis from an infection. In the same vein, low vitamin $\mathrm{K}$ level appears to be associated with increased elastin degradation, ${ }^{191,202}$ preferably degrading the lung tissue, resulting in breathing difficulty in COVID-19 patients. Since COVID-19 patients with severity are associated with co-morbidities such as cardiovascular diseases, type II diabetes, or hypertension, which are linked to reduced vitamin $\mathrm{K}$ levels, it is hypothesized that low vitamin $\mathrm{K}$ levels might be associated with severity in COVID-19. ${ }^{203-205}$

Finally, an exit strategy for a path back to normalcy is required. It should involve a collective effort towards research and development of new treatments and successful vaccine that stems from vitamins and nutrients that can influence viral infections and protect human health. Therefore, it is crucial to develop more effective and practical approaches to investigate the relevance of fat-soluble vitamins as an adjunct therapy for the COVID-19 pandemic.

\section{Five- to Ten-Year Expectation}

Globally, the rapid outbreak of the COVID-19 pandemic is a public health concern as this experience disrupts everyday life activity. Notwithstanding its invasion, minimal evidence-based treatment options are currently available for this infection. Meanwhile, many studies are beginning to recognize the role of different fat-soluble vitamins and micronutrients in combating coronavirus infection. Research has proven their capacity to minimize the severity of this infection. Recent surveys have expatiated that the deficiency of one or more of these vitamins compromises immune response and could cause detrimental effects to the patient. 
However, studies have stated that nutritional strategies for enhancing immunity against viral diseases like COVID-19 have been underexplored, and using these patterns as a therapeutic measure should not be ignored. For instance, the uptake of vitamin $\mathrm{C}$ with its prophylactic effect and its ability to exert immune response for growth and repair of body tissues and its ability to reduce lower respiratory tract infection susceptibility is highly beneficial. ${ }^{33,34}$ Several evidence support the view that COVID-19 disease is particularly detrimental to the health of vulnerable populations like the elderly, pregnant women, and children. Furthermore, older people with longterm chronic conditions of diabetes, cardiovascular diseases, cancer, etc., are well predisposed to COVID-19 infection. The uptake of vitamin $\mathrm{E}$ by these patients is likely to help their immune function, increasing infection resistance, thus decreasing mortality. One more study investigated the potential benefits of vitamin E to COVID-19 patients. ${ }^{1}$ Additionally, it was reported that vitamin $\mathrm{C}$ regenerates the antioxidant potential of vitamin $\mathrm{E},{ }^{2,3}$ and, when administered in combination (vitamin $\mathrm{E}$ and $\mathrm{C}$ ) among critically ill patients, found to be beneficial including COVID-19-infected cases. ${ }^{1,210-215}$ Despite these facts, there is limited evidence that suggests the use of vitamin $\mathrm{E}$ as adjuvant therapy for COVID-19. Therefore, a clear need to investigate these vitamins' prospects as an effective measure in the treatment of COVID-19 is vital. Although investigations into the effect of vitamin $\mathrm{K}$ still seem vague, studies have stated that patients admitted into ICU are potentially at risk of having low levels of this vitamin. Also, there is a need to verify these claims as records have shown that administering vitamin $\mathrm{K}$ supplements to patients during ICU admissions might reduce the risk of vitamin $\mathrm{K}$ deficiency and further health complications. ${ }^{200}$

Finally, even though big data have been presented in prior studies regarding the efficacy of fat-soluble vitamins in immunomodulation and lowering the severity of disease in patients with COVID-19, more detailed clinical pieces of evidence are required to define the use of these supplements in prevention, prophylaxis or reduction of severity in COVID-19 cases. We hope that in the next 5-10 years, clearer, well-established, and substantial evidence to support the prevention and treatment of diseases like coronavirus and other future epidemics will be obtainable.

\section{Author Contributions}

All authors made a significant contribution to the work reported, whether that is in the conception, study design, execution, acquisition of data, analysis, and interpretation, or in all these areas; took part in drafting, revising, or critically reviewing the article; gave final approval of the version to be published; have agreed on the journal to which the article has been submitted; and agree to be accountable for all aspects of the work.

\section{Disclosure}

The authors declare no conflicts of interest in this work.

\section{References}

1. Wintergerst ES, Maggini S, Hornig DH. Contribution of selected vitamins and trace elements to immune function. Ann Nutr Metab. 2007;51(4):301-323. doi:10.1159/000107673

2. Mora JR, Iwata M, von Andrian UH. Vitamin effects on the immune system: vitamins $\mathrm{A}$ and $\mathrm{D}$ take center stage. Nat Rev Immunol. 2008;8(9):685-698. doi:10.1038/nri2378

3. Jayawardena R, Sooriyaarachchi P, Chourdakis M, Jeewandara C, Ranasinghe P. Enhancing immunity in viral infections, with special emphasis on COVID-19: a review. Diabetes Metab Syndr. 2020;14(4):367-382. doi:10.1016/j.dsx.2020.04.015

4. Bhaskaram P. Immunobiology of mild micronutrient deficiencies. Br J Nutr. 2001;85(Suppl 2):S75-80. doi:10.1079/bjn2000297

5. Patel N, Penkert RR, Jones BG, et al. Baseline serum vitamin A and $\mathrm{D}$ levels determine benefit of oral vitamin A\&D supplements to humoral immune responses following pediatric influenza vaccination. Viruses. 2019;11(10):907. doi:10.3390/v11100907

6. Gibson A, Edgar JD, Neville CE, et al. Effect of fruit and vegetable consumption on immune function in older people: a randomized controlled trial. Am J Clin Nutr. 2012;96(6):14291436. doi:10.3945/ajen.112.039057

7. Naik SR, Thakare VN, Joshi FP. Functional foods and herbs as potential immunoadjuvants and medicines in maintaining a healthy immune system: a commentary. J Complement Integer Med. 2010;7(1):Article 46. doi:10.2202/1553-3840.1441

8. Calder PC, Carr AC, Gombart AF, Eggersdorfer M. Optimal Nutritional Status for a Well-Functioning Immune System Is an Important Factor to Protect against Viral Infections. Ann Intern Med. 2020;12(4):1181. doi:10.3390/nu12041181

9. Miller ER 3rd, Pastor-Barriuso R, Dalal D, Riemersma RA, Appel LJ, Guallar E. Meta-analysis: high-dosage vitamin E supplementation may increase all-cause mortality. Ann Intern Med. 2005;142(1):37-46. doi:10.7326/0003-4819-142-1-20050104000110

10. Wu JZ. P. Treatment strategies for reducing damages to lungs in patients with coronavirus and other infections. Preprints. 2020;2020020116.

11. World Health Organization. Food and Nutrition Tips During SelfQuarantine. Europe: Regional office; 2020. Available from: https://www.euro.who.int/en/health-topics/health-emergencies/cor onavirus-covid-19/publications-and-technical-guidance/food-andnutrition-tips-during-self-quarantine. Accessed January 12, 2021.

12. BDA. COVID-19/coronavirus - advice for the general public. 2021. Available from: https://www.bda.uk.com/resource/COVID19-corona-virus-advice-for-the-general-public.html. Accessed January 12, 2021.

13. Curtis LJ, Bernier P, Jeejeebhoy K, et al. Costs of hospital malnutrition. Clin Nutr. 2017;36(5):1391-1396. doi:10.1016/j. clnu.2016.09.009

14. Rytter MJ, Kolte L, Briend A, Friis H, Christensen VB. The immune system in children with malnutrition-a systematic review. PLoS One. 2014;9(8):e105017. doi:10.1371/journal. pone. 0105017 
15. Reber E, Gomes F, Vasiloglou MF, Schuetz P, Stanga Z. Nutritional risk screening and assessment. J Clin Med. 2019;8 (7):1065. doi: $10.3390 / \mathrm{jcm} 8071065$

16. Ssentongo P, Ssentongo AE, Ba DM, et al. Global, regional and national epidemiology and prevalence of child stunting, wasting and underweight in low- and middle-income countries, 2006-2018. Sci Rep. 2021;11(1):5204. doi:10.1038/s41598-02184302-w

17. Birgisdottir BE. Nutrition is key to global pandemic resilience. BMJ Nutr Prev Health. 2020;3(2):129-132. doi:10.1136/bmjnph2020-000160

18. Morais AHA, Aquino JS, da Silva-maia JK, Vale SHL, Maciel BLL, Passos TS. Nutritional status, diet, and viral respiratory infections: perspectives for severe acute respiratory syndrome coronavirus 2. Br J Nutr. 2021;125(8):851-862. doi:10.1017/ $\mathrm{S} 0007114520003311$

19. Malek A, Hashemi M, Anjomrooz M, Torabi P, Imani B Malnutrition and medical nutrition therapy in hospitalized children: a case study of using national malnutrition screening tools in northeastern Iran. Afr Health Sci. 2019;19(1):1566-1573. doi:10.4314/ahs.v19i1.31

20. Volkert D, Beck AM, Cederholm T, et al. Management of malnutrition in older patients-current approaches, evidence and open questions. J Clin Med. 2019;8(7):974. doi:10.3390/ jcm8070974

21. Headey D, Heidkamp R, Osendarp S, et al. Impacts of COVID19 on childhood malnutrition and nutrition-related mortality. Lancet. 2020;396(10250):519-521. doi:10.1016/S0140-6736(20) 31647-0

22. Handu D, Moloney L, Rozga M, Cheng F. Malnutrition care during the COVID-19 pandemic: considerations for registered dietitian nutritionists evidence analysis center. $J$ Acad Nutr Diet. 2020. doi:10.1016/j.jand.2020.05.012

23. Roberton T, Carter ED, Chou VB, et al. Early estimates of the indirect effects of the COVID-19 pandemic on maternal and child mortality in low-income and middle-income countries: a modeling study. Lancet Glob Health. 2020;8(7):e901-e908. doi:10.1016/S2214-109X(20)30229-1

24. Fore HH. A wake-up call: COVID-19 and its impact on children's health and wellbeing. Lancet Glob Health. 2020;8(7):e861-e862. doi:10.1016/S2214-109X(20)30238-2

25. Akseer N, Kandru G, Keats EC, Bhutta ZA. COVID-19 pandemic and mitigation strategies: implications for maternal and child health and nutrition. Am J Clin Nutr. 2020;112(2):251-256. doi:10.1093/ajen/nqaa171

26. Pérez-Escamilla R, Cunningham K, Moran VH. COVID-19 and maternal and child food and nutrition insecurity: a complex syndemic. Matern Child Nutr. 2020;16(3):e13036. doi:10.1111/ mon. 13036

27. UNICEF. An additional 3.9 million children under 5 could suffer from wasting in South Asia this year due to COVID-19 UNICEF. 2020. Available from: https://www.unicef.org/rosa/ press-releases/additional-39-million-children-under-5-could-suf fer-wasting-south-asia-year-due. Accessed April 1, 2021.

28. Brunton C, Arensberg MB, Drawert S, Badaracco C, Everett W, McCauley SM. Perspectives of registered dietitian nutritionists on adoption of telehealth for nutrition care during the COVID-19 pandemic. Healthcare (Basel). 2021;9(2):235. doi:10.3390/ healthcare9020235

29. Rozga M, Handu D, Kelley $\mathrm{K}$, et al. Telehealth during the COVID-19 pandemic: a cross-sectional survey of registered dietitian nutritionists. $J$ Acad Nutr Diet. 2021;S2212-2672 (21):00036. doi:10.1016/j.jand.2021.01.009

30. Hemilä H. Vitamin C and Infections. Nutrients. 2017;9(4):339. doi:10.3390/nu9040339
31. Bakaev VV, Duntau AP. Ascorbic acid in blood serum of patients with pulmonary tuberculosis and pneumonia. Int $J$ Tuberc Lung Dis. 2004;8(2):263-266.

32. Lee SI, Lim CM, Koh Y, Huh JW, Lee JS, Hong SB. The effectiveness of vitamin $\mathrm{C}$ for patients with severe viral pneumonia in respiratory failure. $J$ Thorac Dis. 2021;13(2):632-641. doi:10.21037/jtd-20-1306

33. Carr AC, Maggini S. Vitamin C, and immune function. Nutrients. 2017;9(11):1211. doi:10.3390/nu9111211

34. Hemilä H. Vitamin C intake and susceptibility to pneumonia. Pediatr Infect Dis J. 1997;16(9):836-837. doi:10.1097/ 00006454-199709000-00003

35. Shakoor H, Feehan J, Al Dhaheri AS, et al. Immune-boosting role of vitamins D, C, E, zinc, selenium, and omega-3 fatty acids: could they help against COVID-19? Maturitas. 2021;143:1-9. doi:10.1016/j.maturitas.2020.08.003

36. Name JJ, Souza ACR, Vasconcelos AR, Prado PS, Pereira CPM. Zinc, Vitamin D and Vitamin C: perspectives for COVID-19 with a focus on physical tissue barrier integrity. Front Nutr. 2020;7:606398. doi:10.3389/fnut.2020.606398

37. Boretti A, Banik BK. Intravenous vitamin C for reduction of cytokines storm in acute respiratory distress syndrome. PharmaNutrition. 2020;12:100190. doi:10.1016/j.phanu.2020.100190

38. Holford P, Carr AC, Jovic TH, et al. Vitamin C-an adjunctive therapy for respiratory infection, sepsis and COVID-19. Nutrients. 2020;12(12):3760. doi:10.3390/nu12123760

39. Marik PE. Vitamin C: an essential "stress hormone" during sepsis. $J$ Thorac Dis. 2020;12(Suppl1):S84-S88. doi:10.21037/jtd.2019.12.64

40. Marik PE. Vitamin C for the treatment of sepsis: the scientific rationale. Pharmacol Ther. 2018;189:63-70. doi:10.1016/j. pharmthera.2018.04.007

41. Colunga Biancatelli RML, Berrill M, Marik PE. The antiviral properties of vitamin C. Expert Rev Anti Infect Ther. 2020;18 (2):99-101. doi:10.1080/14787210.2020.1706483

42. Bozonet SM, Carr AC, Pullar JM, Vissers MC. Enhanced human neutrophil vitamin $\mathrm{C}$ status, chemotaxis, and oxidant generation following dietary supplementation with vitamin C-rich SunGold kiwifruit. Nutrients. 2015;7(4):2574-2588. doi:10.3390/nu7042574

43. Kim Y, Kim H, Bae S, et al. Vitamin C is an essential factor on the anti-viral immune responses through the production of interferon- $\alpha /$ $\beta$ at the initial stage of Influenza a Virus (H3N2) infection. Immune Netw. 2013;13(2):70-74. doi:10.4110/in.2013.13.2.70

44. Uozaki M, Ikeda K, Tsujimoto K, et al. Antiviral effects of dehydroascorbic acid. Exp Ther Med. 2010;1(6):983-986. doi:10.3892/etm.2010.139

45. Kim H, Jang M, Kim Y, et al. Red ginseng and vitamin C increase immune cell activity and decrease lung inflammation induced by influenza A virus/H1N1 infection. J Pharm Pharmacol. 2016;68 (3):406-420. doi:10.1111/jphp.12529

46. Wintergerst ES, Maggini S, Hornig DH. Immune-enhancing role of vitamin C and zinc and effect on clinical conditions. Ann Nutr Metab. 2006;50(2):85-94. doi:10.1159/000090495

47. van Gorkom GNY, Klein Wolterink RGJ, Van Elssen CHMJ, Wieten L, Germeraad WTV, Bos GMJ. Influence of Vitamin C on lymphocytes: an overview. Antioxidants (Basel). 2018;7(3):41. doi:10.3390/antiox 7030041

48. Nualart FJ, Rivas CI, Montecinos VP, et al. Recycling of vitamin C by a bystander effect. J Biol Chem. 2003;278(12):1012810133. doi:10.1074/jbc.M210686200

49. Bitetto D, Bortolotti N, Falleti E, et al. Vitamin A deficiency is associated with hepatitis $\mathrm{C}$ virus chronic infection and with unresponsiveness to interferon-based antiviral therapy. Hepatology. 2013;57(3):925-933. doi:10.1002/hep.26186

50. Hall JA, Grainger JR, Spencer SP, Belkaid Y. The role of retinoic acid in tolerance and immunity. Immunity. 2011;35(1):13-22. doi:10.1016/j.immuni.2011.07.002 
51. Field CJ, Johnson IR, Schley PD. Nutrients and their role in host resistance to infection. J Leukoc Biol. 2002;71(1):16-32.

52. Mora JR. Homing imprinting and immunomodulation in the gut: role of dendritic cells and retinoids. Inflamm Bowel Dis. 2008;14 (2):275-289. doi:10.1002/ibd.20280

53. Cunningham-Rundles S, Ahrn S, Abuav-Nussbaum R, Dnistrian A. Development of immunocompetence: role of micronutrients and microorganisms. Nutr Rev. 2002;60(5 Pt 2):S68-72. doi:10.1301/00296640260130777

54. Huang Z, Liu Y, Qi G, Brand D, Zheng SG. Role of Vitamin A in the immune system. J Clin Med. 2018;7(9):258. doi:10.3390/ jcm 7090258

55. Oliveira LM, Teixeira FME, Sato MN. Impact of retinoic acid on immune cells and inflammatory diseases. Mediators Inflamm. 2018;2018:3067126. doi:10.1155/2018/3067126

56. Iyer N, Grizotte-Lake M, Duncan K, et al. Epithelium intrinsic vitamin A signaling coordinates pathogen clearance in the gut via IL-18. PLoS Pathog. 2020;16(4):e1008360. doi:10.1371/journal. ppat. 1008360

57. National Research Council (US) Committee on Diet and Health. Diet and Health: Implications for Reducing Chronic Disease Risk. Washington (DC): National Academies Press (US); 1989. Available from:https://www.ncbi.nlm.nih.gov/books/ NBK218749/. Accessed April 3, 2021.

58. Green AS, Fascetti AJ. Meeting the Vitamin A requirement: the efficacy and importance of $\beta$-Carotene in animal species. ScientificWorldJournal. 2016;2016:7393620. doi:10.1155/2016/ 7393620

59. McCullough FS, Northrop-Clewes CA, Thurnham DI. The effect of vitamin A on epithelial integrity. Proc Nutr Soc. 1999;58 (2):289-293. doi:10.1017/s0029665199000403

60. Raiten DJ, Sakr Ashour FA, Ross AC, et al. Inflammation and Nutritional Science for Programs/Policies and Interpretation of Research Evidence (INSPIRE). J Nutr. 2015;145(5):1039S1108S. doi:10.3945/jn.114.194571

61. Surman SL, Penkert RR, Sealy RE, et al. Consequences of vitamin A deficiency: immunoglobulin dysregulation, squamous cell metaplasia, infectious disease, and death. Int J Mol Sci. 2020;21 (15):5570. doi:10.3390/ijms21155570

62. Semba RD. Vitamin A and immunity to viral, bacterial, and protozoan infections. Proc Nutr Soc. 1999;58(3):719-727. doi:10.1017/s0029665199000944

63. Villamor E, Mbise R, Spiegelman D, et al. Vitamin A supplements ameliorate the adverse effect of HIV-1, malaria, and diarrheal infections on child growth. Pediatrics. 2002;109(1):E6. doi:10.1542/peds.109.1

64. Budhwar S, Sethi K, Chakraborty M, Rapid Advice A. Guideline for the prevention of novel coronavirus through nutritional intervention. Curr Nutr Rep. 2020;9(3):119-128. doi:10.1007/s13668-020-00325-1

65. Irlam JH, Siegfried N, Visser ME, Rollins NC. Micronutrient supplementation for children with HIV infection. Cochrane Database Syst Rev. 2013;(10):CD010666. doi:10.1002/14651858.CD010666

66. Jee J, Hoet AE, Azevedo MP, et al. Effects of dietary vitamin A content on antibody responses of feedlot calves inoculated intramuscularly with an inactivated bovine coronavirus vaccine. Am J Vet Res. 2013;74(10):1353-1362. doi:10.2460/ajvr.74.10.1353

67. Institute of Medicine (US) Committee on Military Nutrition Research. Military Strategies for Sustainment of Nutrition and Immune Function in the Field. Washington (DC): National Academies Press (US); 1999. Available from: https:/www.ncbi. nlm.nih.gov/books/NBK230968/. Accessed April 3, 2021.
68. Kańtoch M, Litwińska B, Szkoda M, Siennicka J. Znaczenie niedoboru witaminy A dla patologii i immunologii zakazeń wirusowych [Importance of vitamin A deficiency in pathology and immunology of viral infections]. Rocz Panstw Zakl Hig. 2002;53 (4):385-392.

69. Stockman LJ, Bellamy R, Garner P. SARS: systematic review of treatment effects. PLoS Med. 2006;3(9):e343. doi:10.1371/journal. pmed.0030343

70. Sa Ribero M, Jouvenet N, Dreux M, Nisole S. Interplay between SARS-CoV-2 and the type I interferon response. PLoS Pathog. 2020;16(7):e1008737. doi:10.1371/journal.ppat.1008737

71. Lokugamage KG, Hage A, de Vries M, et al. Type I interferon susceptibility distinguishes SARS-CoV-2 from SARS-CoV. $J$ Virol. 2020;94(23):e01410-20. doi:10.1128/JVI.01410-20

72. Chelstowska S, Widjaja-Adhi MA, Silvaroli JA, Golczak M. Molecular Basis for Vitamin an Uptake and Storage in Vertebrates. Nutrients. 2016;8(11):676. doi:10.3390/nu8110676

73. Trasino SE. A role for retinoids in the treatment of COVID-19?. Clin Exp Pharmacol Physiol 2020;47(10):1765-1767. doi:10.1111/14401681.13354

74. Gudas LJ. Emerging roles for retinoids in regeneration and differentiation in normal and disease states. Biochim Biophys Acta. 2012;1821(1):213-221. doi:10.1016/j.bbalip.2011.08.002

75. Rusu A, Tanase C, Pascu GA, Todoran N. Recent advances regarding the therapeutic potential of adapalene. Pharmaceuticals (Basel). 2020;13(9):217. doi:10.3390/ph13090217

76. Midha IK, Kumar N, Kumar A, Madan T. Mega-doses of retinol: a possible immunomodulation in Covid-19 illness in resource-limited settings. Rev Med Virol. 2020;e2204. doi:10.1002/rmv.2204

77. Jovic TH, Ali SR, Ibrahim N, et al. Could Vitamins Help in the Fight Against COVID-19? Nutrients. 2020;12(9):2550. doi:10.3390/nu12092550

78. Li R, Wu K, Li Y, et al. Revealing the targets and mechanisms of vitamin $\mathrm{A}$ in the treatment of COVID-19. Aging (Albany NY). 2020;12(15):15784-15796. doi:10.18632/aging.103888

79. Gröber U, Holick MF. The coronavirus disease (COVID-19) - A supportive approach with selected micronutrients. Int J Vitam Nutr Res. 2021;1-22. doi:10.1024/0300-9831/a000693

80. Al-Sumiadai MM, Ghazzay H, Al-Dulaimy WZS. Therapeutic effect of Vitamin A on severe COVID-19 patients. Eurasia $J$ Biosci. 2020;14:7347-7350. doi:10.31838/SRP.2021.1.33

81. Michienzi SM, Badowski ME. Can vitamins and/or supplements provide hope against coronavirus? Drugs Context. 2020;9:2020. doi:10.7573/dic.2020-5-7

82. Fiorino S, Gallo C, Zippi M, et al. Cytokine storm in aged people with CoV-2: possible role of vitamins as therapy or preventive strategy. Aging Clin Exp Res. 2020;32(10):2115-2131. doi:10.1007/s40520-020-01669-y

83. Stephensen CB, Lietz G.Vitamin A in resistance to and recovery from infection: relevance to SARS-CoV2. Br J Nutr. 2021;1-10. doi:10.1017/S0007114521000246

84. D'Souza RM, D'Souza R. Vitamin A for preventing secondary infections in children with measles-a systematic review. J Trop Pediatr. 2002;48(2):72-77. doi:10.1093/tropej/48.2.72.84

85. McGill JL, Kelly SM, Guerra-Maupome M, et al. Vitamin A deficiency impairs the immune response to intranasal vaccination and RSV infection in neonatal calves. Sci Rep. 2019;9(1):15157. doi:10.1038/s41598-019-51684-x

86. Timoneda J, Rodríguez-Fernández L, Zaragozá R, et al. Vitamin A deficiency and the lung. Nutrients. 2018;10(9):1132. doi:10.3390/ nu10091132 
87. Biesalski HK, Nohr D. Importance of vitamin-A for lung function and development. Mol Aspects Med. 2003;24(6):431-440. doi:10.1016/s0098-2997(03)00039-6

88. Sarohan AR. COVID-19: endogenous retinoic acid theory and retinoic acid depletion syndrome. Med Hypotheses. 2020;144:110250. doi:10.1016/j.mehy.2020.110250

89. Thirumdas R, Kothakota A, Pandiselvam R, Bahrami A, Barba FJ. Role of food nutrients and supplementation in fighting against viral infections and boosting immunity: a review. Trends Food Sci Technol. 2021;110:66-77. doi:10.1016/j. tifs.2021.01.069

90. Gombart AF. The vitamin D-antimicrobial peptide pathway and its role in protection against infection. Future Microbiol. 2009;4 (9):1151-1165. doi:10.2217/fmb.09.87

91. Panfili FM, Roversi M, D’Argenio P, Rossi P, Cappa M, Fintini D. Possible role of vitamin D in COVID-19 infection in pediatric population. J Endocrinol Invest. 2021;44(1):27-35. doi:10.1007/s40618-02001327-0

92. Charoenngam N, Shirvani A, Kalajian TA, Song A, Holick MF. The effect of various doses of oral Vitamin D3 supplementation on gut microbiota in healthy adults: a randomized, doubleblinded, dose-response study. Anticancer Res. 2020;40(1):551556. doi:10.21873/anticanres. 13984

93. Thacher TD, Clarke BL. Vitamin D insufficiency. Mayo Clin Proc. 2011;86(1):50-60. doi:10.4065/mcp.2010.0567

94. Ilie PC, Stefanescu S, Smith L. The role of vitamin D in the prevention of coronavirus disease 2019 infection and mortality. Aging Clin Exp Res. 2020;32(7):1195-1198. doi:10.1007/ s40520-020-01570-8

95. Biesalski HK. Vitamin D deficiency and co-morbidities in COVID-19 patients - a fatal relationship? NFS Journal. 2020;20:10-21. doi:10.1016/j.nfs.2020.06.001

96. Martineau AR, Jolliffe DA, Hooper RL, et al. Vitamin D supplementation to prevent acute respiratory tract infections: systematic review and meta-analysis of individual participant data. $B M J$. 2017;356:i6583. doi:10.1136/bmj.i6583

97. Lips P, Cashman KD, Lamberg-Allardt C, et al. Current vitamin D status in European and Middle East countries and strategies to prevent vitamin D deficiency: a position statement of the European Calcified Tissue Society. Eur J Endocrinol. 2019;180 (4):P23-P54. doi:10.1530/EJE-18-0736

98. Taylor CL, Thomas PR, Aloia JF, Millard PS, Rosen CJ. Questions about Vitamin D for primary care practice: input from an NIH conference. Am J Med. 128(11):1167-1170. doi:10.1016/j.amjmed.2015.05.025

99. Calvo MS, Whiting SJ, Barton CN. Vitamin D fortification in the United States and Canada: current status and data needs. $\mathrm{Am} \mathrm{J}$ Clin Nutr. 2004;80(6Suppl):1710S-6S. doi:10.1093/ajen/ 80.6.1710S

100. Martineau AR, Nanzer AM, Satkunam KR, et al. Influence of a single oral dose of vitamin D (2) on serum 25-hydroxyvitamin D concentrations in tuberculosis patients. Int $J$ Tuberc Lung Dis. 2009;13(1):119-125.

101. Ebadi M, Montano-Loza AJ. Perspective: improving vitamin D status in the management of COVID-19. Eur J Clin Nutr. 2020;74 (6):856-859. doi:10.1038/s41430-020-0661-0

102. Kimball SM, Mirhosseini N, Holick MF. Evaluation of vitamin D3 intakes up to 15,000 international units/day and serum 25-hydroxyvitamin D concentrations up to $300 \mathrm{nmol} /$ L on calcium metabolism in a community setting. DermatoEndocrinology. 2017;9(1):e1300213. doi:10.1080/ 19381980.2017.1300213
103. Wang $\mathrm{D}, \mathrm{Hu} \mathrm{B}, \mathrm{Hu} \mathrm{C}$, et al. Clinical characteristics of 138 hospitalized patients with 2019 novel coronavirus-infected pneumonia in Wuhan, China. JAMA. 2020;323(11):1061-1069.

104. CIDRAP - Center for Infectious Disease Research and Policy. COVID-19 Sickens Over 1,700 Health Workers in China, Killing 6. Office of the Vice President for Research. Minneapolis, MN: University of Minnesota; 2020. Available athttps://www.cidrap.umn.edu/news-perspective/2020/02/ covid-19-sickens-over-1700-health-workers-china-killing-6. Accessed on April 4, 2021].

105. Bandyopadhyay S, Baticulon RE, Kadhum M, et al. Infection and mortality of healthcare workers worldwide from COVID-19: a systematic review. BMJ Glob Health. 2020;5(12):e003097. doi:10.1136/bmjgh-2020-003097

106. Kincaid E. One Year into the Pandemic, More Than 3000 Healthcare Workers Have Died of COVID-19. Medscape. Editor's note: find the latest COVID-19 news and guidance in Medscape's Coronavirus Resource Center. 2021. Available from: https://www.medscape.com/viewarticle/947304\#: :text=One\% 20 Year\%20Into $\% 20$ the $\% 20$ Pandemic,Have $\% 20$ Died $\% 20$ of $\%$ 20COVID\%2D19\&text=Editor's\%20note\%3A\%20Find\%20the\% 201atest,in\%20Medscape's\%20Coronavirus\%20Resource\% 20Center. Accessed April 2, 2021.

107. Melimopoulos E At least 17,000 health workers have died from COVID: amnesty. Aljazeera Media Network. 2021. Available from: https://www.aljazeera.com/news/2021/3/5/at-least-17000-healthworkers-have-died-from-covid-amnesty. Accessed April 2, 2021

108. Quraishi SA, Bittner EA, Blum L, Hutter MM, Camargo CA Jr. Association between preoperative 25-hydroxyvitamin D level and hospital-acquired infections following Roux-en-Y gastric bypass surgery. JAMA Surg. 2014;149(2):112-118. doi:10.1001/jamasurg.2013.3176

109. Laviano E, Sanchez Rubio M, González-Nicolás MT, et al. Association between preoperative levels of 25-hydroxyvitamin $\mathrm{D}$ and hospital-acquired infections after hepatobiliary surgery: a prospective study in a third-level hospital. PLoS One. 2020;15(3): e0230336. doi:10.1371/journal.pone.0230336

110. Quraishi SA, Litonjua AA, Moromizato T, et al. Association between prehospital vitamin D status and hospital-acquired bloodstream infections. Am J Clin Nutr. 2013;98(4):952-959. doi:10.3945/ajen.113.058909

111. Amrein K, Litonjua AA, Moromizato $\mathrm{T}$, et al. Increases in prehospitalization serum $25(\mathrm{OH}) \mathrm{D}$ concentrations are associated with improved 30-day mortality after hospital admission: a cohort study. Clin Nutr. 2016;35(2):514-521. doi:10.1016/j.clnu.2015.03.020

112. Grant WB, Lahore H, McDonnell SL, et al. Evidence that Vitamin D supplementation could reduce risk of influenza and COVID-19 Infections and Deaths. Nutrients. 2020;12(4):988. doi:10.3390/nu12040988

113. Grant WB, Al Anouti F, Moukayed M. Targeted 25-hydroxyvitamin D concentration measurements and vitamin D3 supplementation can have important patient and public health benefits. Eur $J$ Clin Nutr. 2020;74(3):366-376. doi:10.1038/s41430-020-0564-0

114. Gunville CF, Mourani PM, Ginde AA. The role of vitamin D in prevention and treatment of infection. Inflamm Allergy Drug Targets. 2013;12(4):239-245. doi:10.2174/18715281113129990046

115. Baqi HR, Farag HAM, El Bilbeisi AHH, Askandar RH, El Afifi AM. Oxidative stress and its association with COVID-19: a narrative review. Kurdistan $J$ Appl Res. 2020;97-105. doi:10.24017/covid.11

116. Delgado-Roche L, Mesta F. Oxidative stress as key player in severe acute respiratory syndrome coronavirus (SARS-CoV) infection. Arch Med Res. 2020;51(5):384-387. doi:10.1016/j. arcmed.2020.04.019 
117. Hariharan A, Hakeem AR, Radhakrishnan S, Reddy MS, Rela M. The role and therapeutic potential of NF-Kappa-B pathway in severe COVID-19 patients. Inflammopharmacology. 2021;29 (1):91-100. doi:10.1007/s10787-020-00773-9

118. Al-Lami RA, Urban RJ, Volpi E, Algburi AMA, Baillargeon J. Sex hormones and novel corona virus infectious disease (COVID19). Mayo Clin Proc. 2020;95(8):1710-1714. doi:10.1016/j. mayocp.2020.05.013

119. de Las Heras N, Martín Giménez VM, Ferder L, Manucha W, Lahera V. Implications of oxidative stress and potential role of mitochondrial dysfunction in COVID-19: therapeutic effects of Vitamin D. Antioxidants (Basel). 2020;9(9):897. doi:10.3390/ antiox9090897

120. Kozlov EM, Ivanova E, Grechko AV, Wu WK, Starodubova AV, Orekhov AN. Involvement of oxidative stress and the innate immune system in SARS-CoV-2 infection. Diseases. 2021;9 (1):17. doi:10.3390/diseases 9010017

121. Xu Z, Shi L, Wang Y, et al. Pathological findings of COVID-19 associated with acute respiratory distress syndrome. Lancet Respir Med. 2020;8(4):420-422. doi:10.1016/S2213-2600(20) 30076-X

122. Di Vincenzo A, Tana C, El Hadi H, Pagano C, Vettor R, Rossato M. Antioxidant, anti-inflammatory, and metabolic properties of tocopherols and tocotrienols: clinical implications for Vitamin E supplementation in diabetic kidney disease. Int $\mathrm{J} \mathrm{Mol} \mathrm{Sci.}$ 2019;20(20):5101. doi:10.3390/ijms20205101

123. Freedman JE, Keaney JF Jr. Vitamin E inhibition of platelet aggregation is independent of antioxidant activity. $J$ Nutr. 2001;131(2):374S-7S. doi:10.1093/jn/131.2.374S

124. Ntyonga-Pono MP. COVID-19 infection and oxidative stress: an under-explored approach for prevention and treatment? Pan Afr Med J. 2020;35(Suppl 2):12. doi:10.11604/pamj.2020.35.2.22877

125. Wu D, Lewis ED, Pae M, Meydani SN. Nutritional modulation of immune function: analysis of evidence, mechanisms, and clinical relevance. Front Immunol. 2019;9:3160. doi:10.3389/fimmu. 2018.03160

126. Coquette A, Vray B, Vanderpas J. Role of vitamin E in the protection of the resident macrophage membrane against oxidative damage. Arch Int Physiol Biochim. 1986;94(5):S29-34.

127. Zhai T, Li S, Hu W, Li D, Leng S. Potential micronutrients and phytochemicals against the pathogenesis of chronic obstructive pulmonary disease and lung cancer. Nutrients. 2018;10(7):813. doi:10.3390/nu10070813

128. Lee CY, Man-Fan Wan J. Vitamin E supplementation improves cell-mediated immunity and oxidative stress of Asian men and women. $J$ Nutr. 2000;130(12):2932-2937. doi:10.1093/jn/ 130.12 .2932

129. Bivona JJ 3rd, Patel S, Vajdy M. Induction of cellular and molecular Immunomodulatory pathways by vitamin E and vitamin C. Expert Opin Biol Ther. 2017;17(12):1539-1551. doi:10.1080/ 14712598.2017.1375096

130. Lobo V, Patil A, Phatak A, Chandra N. Free radicals, antioxidants, and functional foods: impact on human health. Pharmacogn Rev. 2010;4(8):118-126. doi:10.4103/09737847.70902

131. Kurutas EB. The importance of antioxidants which play the role in cellular response against oxidative/nitrosative stress: current state. Nutr J. 2016;15(1):71. doi:10.1186/s12937-016-0186-5

132. Haider K, Haider MR, Neha K, Yar MS. Free radical scavengers: an overview on heterocyclic advances and medicinal prospects. Eur $J$ Med Chem. 2020;204:112607. doi:10.1016/j.ejmech.2020.112607

133. Cecchini R, Cecchini AL. SARS-CoV-2 infection pathogenesis is related to oxidative stress as a response to aggression. Med Hypotheses. 2020;143:110102. doi:10.1016/j.mehy.2020.110102
134. Niki E. Evidence for beneficial effects of vitamin E. Korean $J$ Intern Med. 2015;30(5):571-579. doi:10.3904/ kjim.2015.30.5.571

135. Traber MG, Atkinson J. Vitamin E, antioxidant, and nothing more. Free Radic Biol Med. 2007;43(1):4-15. doi:10.1016/j. freeradbiomed.2007.03.024

136. Li Y, Zhou W, Yang L, You R. Physiological and pathological regulation of ACE2, the SARS-CoV-2 receptor. Pharmacol Res. 2020;157:104833. doi:10.1016/j.phrs.2020.104833

137. Chaplin DD. Overview of the immune response. $J$ Allergy Clin

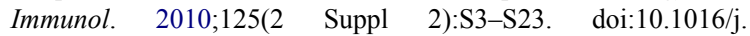
jaci.2009.12.980

138. Cronkite DA, Strutt TM. The regulation of inflammation by innate and adaptive lymphocytes. $J$ Immunol Res. 2018;2018:1467538. doi:10.1155/2018/1467538

139. Janeway CA Jr, Travers $\mathrm{P}$, Walport $\mathrm{M}$, et al. Immunobiology: The Immune System in Health and Disease. 5th ed. New York: Garland Science; 2001. Available from: https://www.ncbi.nlm. nih.gov/books/NBK27090/. Accessed April 4, 2021.

140. de Wit E, van Doremalen N, Falzarano D, Munster VJ. SARS and MERS: recent insights into emerging coronaviruses. Nat Rev Microbiol. 2016;14(8):523-534. doi:10.1038/nrmicro.2016.81

141. Mehta P, McAuley DF, Brown M, et al. COVID-19: consider cytokine storm syndromes and immunosuppression. Lancet. 2020;395 (10229):1033-1034. doi:10.1016/S0140-6736(20)30628-0

142. Ye Q, Wang B, Mao J. The pathogenesis and treatment of the 'Cytokine Storm' in COVID-19. J Infect. 2020;80(6):607-613. doi:10.1016/j.jinf.2020.03.037

143. Moriguchi S, Vitamin MM. E and immunity. Vitam Horm. 2000;59:305-336. doi:10.1016/s0083-6729(00)59011-6

144. Zabetakis I, Lordan R, Norton C, Tsoupras A. COVID-19: the inflammation link and the role of nutrition in potential mitigation. Nutrients. 2020;12(5):1466. doi:10.3390/nu12051466

145. Tanaka J, Fujiwara H, Torisu M. Vitamin E and immune response. I. Enhancement of Helper $T$ Cell Activity by Dietary Supplementation of Vitamin E in Mice. Immunology. 1979;38 (4):727-734.

146. Lewis ED, Meydani SN, Wu D. Regulatory role of vitamin $\mathrm{E}$ in the immune system and inflammation. IUBMB Life. 2019;71 (4):487-494. doi:10.1002/iub.1976

147. Lee GY, Han SN. The role of Vitamin E in immunity. Nutrients. 2018;10(11):1614. doi:10.3390/nu10111614

148. Subedi L, Tchen S, Gaire BP, Hu B, Hu K. Adjunctive nutraceutical therapies for COVID-19. Int J Mol Sci. 2021;22(4):1963. doi:10.3390/ijms22041963

149. Bae M, Kim H. Mini-review on the roles of vitamin C, vitamin $\mathrm{D}$, and selenium in the immune system against COVID-19. Molecules. 2020;25(22):5346. doi:10.3390/ molecules 25225346

150. Hamulka J, Jeruszka-Bielak M, Górnicka M, Drywień ME, Zielinska-Pukos MA. Dietary Supplements during COVID-19 outbreak. Results of Google Trends analysis supported by PLifeCOVID-19 online studies. Nutrients. 2020;13(1):54. doi: $10.3390 /$ nu13010054

151. Center for Disease Control and Prevention. Older Adults. At Greater Risk of Requiring Hospitalization or Dying if Diagnosed with COVID-19. National Center for Immunization and Respiratory Diseases (NCIRD), Division of Viral Diseases. 2021. Available from: https://www.cdc.gov/coronavirus/2019-ncov/need-extra-pre cautions/older-adults.html\#. Accessed April 4, 2021.

152. Allotey J, Stallings E, Bonet M, et al. Clinical manifestations, risk factors, and maternal and perinatal outcomes of coronavirus disease 2019 in pregnancy: living systematic review and meta-analysis. BMJ. 2020;370:m3320. doi:10.1136/bmj.m3320 
153. Hu YJ, Wake M, Saffery R. Clarifying the sweeping consequences of COVID-19 in pregnant women, newborns, and children with existing cohorts. JAMA Pediatr. 2021;175(2):117-118. doi:10.1001/jamapediatrics.2020.2395

154. Liu H, Wang LL, Zhao SJ, Kwak-Kim J, Mor G, Liao AH. Why are pregnant women susceptible to COVID-19? An immunological viewpoint. J Reprod Immunol. 2020;139:103122. doi:10.1016/ j.jri.2020.103122

155. Buekens P, Alger J, Bréart G, Cafferata ML, Harville E, Tomasso G. A call for action for COVID-19 surveillance and research during pregnancy. Lancet Glob Health. 2020;8(7):e877-e878. doi:10.1016/ S2214-109X(20)30206-0

156. Yee J, Kim W, Han JM, et al. Clinical manifestations and perinatal outcomes of pregnant women with COVID-19: a systematic review and meta-analysis. Sci Rep. 2020;10(1):18126. doi:10.1038/s41598-020-75096-4

157. Mueller AL, McNamara MS, Sinclair DA. Why does COVID-19 disproportionately affect older people? Aging (Albany NY). 2020;12(10):9959-9981. doi:10.18632/aging.103344

158. Khan M, Khan H, Khan S, Nawaz M. Epidemiological and clinical characteristics of coronavirus disease (COVID-19) cases at a screening clinic during the early outbreak period: a single-center study. $J$ Med Microbiol. 2020;69(8):1114-1123. doi:10.1099/jmm.0.001231

159. Genebat M, Tarancón-Díez L, de Pablo-bernal R, Calderón A, Muñoz-Fernández MÁ, Leal M. Coronavirus Disease (COVID19): a perspective from immunosenescence. Aging Dis. 2021;12 (1):3-6. doi:10.14336/AD.2020.0831

160. Castelo-Branco C, Soveral I. The immune system and aging: a review. Gynecol Endocrinol. 2014;30(1):16-22. doi:10.3109/ 09513590.2013 .852531

161. Meydani SN, Lewis ED, Wu D. Perspective: should Vitamin E recommendations for older adults be increased? Adv Nutr. 2018;9 (5):533-543. doi:10.1093/advances/nmy035

162. Wu D, Meydani SN. Age-associated changes in immune function: impact of vitamin $\mathrm{E}$ intervention and the underlying mechanisms. Endocr Metab Immune Disord Drug Targets. 2014;14(4):283289. doi:10.2174/1871530314666140922143950

163. Meydani SN, Han SN, Wu D. Vitamin E and immune response in the aged: molecular mechanisms and clinical implications. Immunol Rev. 2005;205(1):269-284. doi:10.1111/j.0105-2896.2005.00274.x

164. Morelli MB, Gambardella J, Castellanos V, Trimarco V, Santulli G Vitamin C and Cardiovascular Disease: an Update. Antioxidants (Basel). 2020;9(12):1227. doi:10.3390/antiox9121227

165. Liu F, Zhu Y, Zhang J, Li Y, Peng Z. Intravenous high-dose vitamin $\mathrm{C}$ for the treatment of severe COVID-19: study protocol for a multicentre randomized controlled trial. BMJ Open. 2020;10 (7):e039519. doi:10.1136/bmjopen-2020-039519

166. Beigmohammadi MT, Bitarafan S, Hoseindokht A, et al. Impact of vitamins A, B, C, D, and E supplementation on improvement and mortality rate in ICU patients with coronavirus-19: a structured summary of a study protocol for a randomized controlled trial. Trials. 2020;21(1):614. doi:10.1186/s13063-020-04547-0

167. Prasad K, McNair ED, Qureshi AM, Casper-Bell G. Vitamin E slows the progression of hypercholesterolemia-induced oxidative stress in heart, liver, and kidney. Mol Cell Biochem. 2012;368(12):181-187. doi:10.1007/s11010-012-1358-z

168. Moser MA, Chun OK. Vitamin $\mathrm{C}$ and heart health: a review based on findings from epidemiologic studies. Int J Mol Sci. 2016;17 (8):1328. doi:10.3390/ijms17081328

169. Azkur AK, Akdis M, Azkur D, et al. Immune response to SARSCoV-2 and mechanisms of immunopathological changes in COVID19. Allergy. 2020;75(7):1564-1581. doi:10.1111/all.14364

170. Michele CA, Angelo B, Valeria L, Teresa M, Pasquale DL. Vitamin supplements in the Era of SARS-CoV2 pandemic. GSC Biol Pharm Sci. 2020;11(02):007-019. doi:10.30574/ gscbps.2020.11.2.0114
171. Gao X, Wilde PE, Lichtenstein AH, Bermudez OI, Tucker KL. The maximal amount of dietary alpha-tocopherol intake in U.S. adults (NHANES 2001-2002). J Nutr. 2006;136(4):1021-1026. doi:10.1093/jn/136.4.1021

172. Xu Y, Baylink DJ, Chen CS, et al. The importance of vitamin D metabolism as a potential prophylactic, immunoregulatory, and neuroprotective treatment for COVID-19. J Transl Med. 2020;18 (1):322. doi:10.1186/s12967-020-02488-5

173. Owen KN, Dewald O. Vitamin E Toxicity. [Updated 2020 Nov 20]. In: StatPearls [Internet]. Treasure Island (FL): StatPearls Publishing; 2021. Available from https://www.ncbi.nlm.nih.gov/ books/NBK564373/. Accessed April 4, 2021.

174. Brody T. Nutritional Biochemistry. 2nd ed ed. San Diego: Academic Press; 1999.

175. Maresz K. Proper calcium use: vitamin K2 as a promoter of bone and cardiovascular health. Integr Med (Encinitas). 2015;14 (1):34-39.

176. Shearer MJ. Vitamin K. Lancet. 1995;345(8944):229-234. doi:10.1016/s0140-6736(95)90227-9

177. Holmes MV, Hunt BJ, Shearer MJ. The role of dietary vitamin K in the management of oral vitamin $\mathrm{K}$ antagonists. Blood Rev. 2012;26(1):1-14. doi:10.1016/j.blre.2011.07.002

178. Booth SL. Vitamin K: food composition and dietary intakes. Food Nutr Res. 2012;56. doi:10.3402/fnr.v56i0.5505

179. Eden RE, Coviello JM. Vitamin K Deficiency. [Updated 2020 Nov 21]. StatPearls [Internet]. Treasure Island (FL): StatPearls Publishing; 2021Jan-. Available from: https://www.ncbi.nlm.nih. gov/books/NBK536983/. Accessed December 10, 2020.

180. Trumbo P, Yates AA, Schlicker S, Poos M. Dietary reference intakes: vitamin $\mathrm{A}$, vitamin $\mathrm{K}$, arsenic, boron, chromium, copper, iodine, iron, manganese, molybdenum, nickel, silicon, vanadium, and zinc. J Am Diet Assoc. 2001;101(3):294-301. doi:10.1016/ S0002-8223(01)00078-5

181. Booth SL. Roles for vitamin K beyond coagulation. Annu Rev Nutr. 2009;29:89-110. doi:10.1146/annurev-nutr-080508-141217

182. Schurgers LJ, Spronk HM, Soute BA, Schiffers PM, DeMey JG, Vermeer C. Regression of warfarin-induced medial elastocalcinosis by high intake of vitamin $\mathrm{K}$ in rats. Blood. 2007;109(7):28232831. doi:10.1182/blood-2006-07-035345

183. Mukai K, Itoh S, Morimoto H. Stopped-flow kinetic study of vitamin $\mathrm{E}$ regeneration reaction with biological hydroquinones (reduced forms of ubiquinone, vitamin $\mathrm{K}$, and tocopherolquinone) in solution. J Biol Chem. 1992;267(31):22277-22281.

184. Vervoort LM, Ronden JE, Thijssen HH. The potent antioxidant activity of the vitamin $\mathrm{K}$ cycle in microsomal lipid peroxidation. Biochem Pharmacol. 1997;54(8):871-876. doi:10.1016/s00062952(97)00254-2

185. Hodges SJ, Pitsillides AA, Ytrebø LM, Soper R. Anti-inflammatory actions of vitamin K. In: Vitamin K2: Vital for Health and Wellbeing. 2017;153.

186. Olson RE. Vitamin K. In: Shils M, Olson JA, Shike M, Ross AC, editors. Modern Nutrition in Health and Disease. 9th ed. Baltimore: Lippincott Williams \& Wilkins; 1999:363-380.

187. Shearer MJ. Vitamin K deficiency bleeding (VKDB) in early infancy. Blood Rev. 2009;23(2):49-59. doi:10.1016/j.blre.2008.06.001

188. Institute of Medicine (US) Panel on Micronutrients. Dietary Reference Intakes for Vitamin A, Vitamin K, Arsenic, Boron, Chromium, Copper, Iodine, Iron, Manganese, Molybdenum, Nickel, Silicon, Vanadium, and Zinc. Washington (DC): National Academies Press (US); 2001.

189. Institute of Medicine (US) Subcommittee on Interpretation and Uses of Dietary Reference Intakes; Institute of Medicine (US) Standing Committee on the Scientific Evaluation of Dietary Reference Intakes. DRI Dietary Reference Intakes: Applications in Dietary Assessment. Washington (DC): National Academies Press (US); 2000. 
190. McPherson C. Vitamin K deficiency bleeding: an ounce of prevention. Neonatal Netw. 2020;39(6):356-362. doi:10.1891/07300832/11-T-630

191. Dofferhoff ASM, Piscaer I, Schurgers LJ, et al. Reduced vitamin $\mathrm{K}$ status as a potentially modifiable risk factor of severe COVID-19. Clin Infect Dis. 2020:ciaa1258. doi:10.1093/cid/ciaa1258.

192. Speed V, Patel RK, Byrne R, Roberts LN, Arya R. A perfect storm: root cause analysis of supra-therapeutic anticoagulation with vitamin $\mathrm{K}$ antagonists during the COVID-19 pandemic. Thromb Res. 2020;192:73-74. doi:10.1016/j. thromres.2020.05.024

193. Marsden J, Darke S, Hall W, et al. Mitigating and learning from the impact of COVID-19 infection on addictive disorders. Addiction. 2020;115(6):1007-1010. doi:10.1111/add.15080

194. Hylek EM, Heiman H, Skates SJ, Sheehan MA, Singer DE. Acetaminophen and other risk factors for excessive warfarin anticoagulation. JAMA. 1998;279(9):657-662. doi:10.1001/ jama.279.9.657

195. Tang N, Li D, Wang X, Sun Z. Abnormal coagulation parameters are associated with poor prognosis in patients with novel coronavirus pneumonia. J Thromb Haemost. 2020;18(4):844-847. doi:10.1111/jth. 14768

196. Hamblin J. Why Some People Get Sicker Than Others COVID19 is proving to be a disease of the immune system. This could, in theory, be controlled. 2020. Available from: https://www.theatlan tic.com/health/archive/2020/04/coronavirus-immune-response/ 610228/. Accessed January 12, 2021.

197. Velavan TP, Meyer CG. Mild versus severe COVID-19: laboratory markers. Int J Infect Dis. 2020;95:304-307. doi:10.1016/j. ijid.2020.04.061

198. Turshudzhyan A. Anticoagulation Options for Coronavirus Disease 2019 (COVID-19)-induced coagulopathy. Cureus. 2020;12(5):e8150. doi:10.7759/cureus.8150

199. Chakraverty R, Davidson S, Peggs K, Stross P, Garrard C, Littlewood TJ. The incidence and cause of coagulopathies in an intensive care population. Br J Haematol. 1996;93(2):460-463. doi:10.1046/j.1365-2141.1996.5101050.x

200. Crowther MA, McDonald E, Johnston M, Cook D. Vitamin K deficiency and D-dimer levels in the intensive care unit: a prospective cohort study. Blood Coagul Fibrinolysis. 2002;13(1):4952. doi:10.1097/00001721-200201000-00007

201. Becker RC. COVID-19 update: COVID-19-associated coagulopathy. J Thromb Thrombolysis. 2020;50(1):54-67. doi:10.1007/ s11239-020-02134-3

202. Piscaer I, van den Ouweland JMW, Vermeersch K, et al. Low Vitamin $\mathrm{K}$ status is associated with increased elastin degradation in chronic obstructive pulmonary disease. J Clin Med. 2019;8 (8):1116. doi: $10.3390 /$ jcm 8081116

203. Riphagen IJ, Keyzer CA, Drummen NEA, et al. Prevalence and Effects of Functional Vitamin K Insufficiency: the PREVEND Study. Nutrients. 2017;9(12):E1334. doi:10.3390/nu9121334
204. Huang C, Wang Y, Li X, et al. Clinical features of patients infected with 2019 novel coronavirus in Wuhan, China. Lancet. 2020;395(10223):497-506. doi:10.1016/S0140-6736(20)30183-5

205. Zhou F, Yu T, Du R, et al. Clinical course and risk factors for mortality of adult inpatients with COVID-19 in Wuhan, China: a retrospective cohort study. Lancet. 2020;395(10229):1054-1062. doi:10.1016/S0140-6736(20)30566-3

206. Obe BH, Retter A, McClintock C. Practical guidance for the prevention of thrombosis and management of coagulopathy and disseminated intravascular coagulation of patients infected with COVID-19. 2020. Available from: https://academy.isth.org/isth/document_library?dc_ id $=9449 \& \mathrm{f}=$ menu $\% 3 \mathrm{D} 8 \% 2$ Abrowseby $\% 3$ D $8 \% 2$ Asortby $\% 3 \mathrm{D} 2 \%$ 2Alabel\%3D19794. Accessed April 6, 2021.

207. Thachil J, Tang N, Gando S, et al. DOACs and "newer" hemophilia therapies in COVID-19: reply. J Thromb Haemost. 2020;18 (7):1795-1796. doi:10.1111/jth.14841

208. Thorp JA, Gaston L, Caspers DR, Pal ML. Current concepts and controversies in the use of vitamin K. Drugs. 1995;49(3):376387. doi:10.2165/00003495-199549030-00005

209. Reiffel JA. An important indirect drug interaction between dronedarone and warfarin that may be extrapolated to other drugs that can alter gastrointestinal function. Am Heart J. 2011;161(2): e5.

210. Soto ME, Guarner-Lans V, Soria-Castro E, Manzano Pech L, Is Antioxidant P-TI. Therapy a useful complementary measure for Covid-19 treatment? An algorithm for its application. Medicina (Kaunas). 2020;56(8):386. doi:10.3390/medicina56080386

211. Nathens AB, Neff MJ, Jurkovich GJ, et al. Randomized, prospective trial of antioxidant supplementation in critically ill surgical patients. Ann Surg. 2002;236(6):814-822. doi:10.1097/00000658200212000-00014

212. Traber MG, Stevens JF. Vitamins C and E: beneficial effects from a mechanistic perspective. Free Radic Biol Med. 2011;51 (5):1000-1013. doi:10.1016/j.freeradbiomed.2011.05.017

213. Crimi E, Liguori A, Condorelli M, et al. The beneficial effects of antioxidant supplementation in enteral feeding in critically ill patients: a prospective, randomized, double-blind, placebo-controlled trial. Anesth Analg. 2004;99(3):857-63, table of contents. doi:10.1213/01.ANE.0000133144.60584.F6

214. Howe KP, Clochesy JM, Goldstein LS, Owen H. Mechanical ventilation antioxidant trial. Am J Crit Care. 2015;24(5):440445. doi:10.4037/ajcc2015335

215. Preiser JC, Van Gossum A, Berré J, Vincent JL, Carpentier Y. Enteral feeding with a solution enriched with antioxidant vitamins A, C, and E enhances the resistance to oxidative stress. Crit Care Med. 2000;28(12):3828-3832. doi:10.1097/00003246-2000 12000-00013
Journal of Inflammation Research

\section{Publish your work in this journal}

The Journal of Inflammation Research is an international, peerreviewed open-access journal that welcomes laboratory and clinical findings on the molecular basis, cell biology and pharmacology of inflammation including original research, reviews, symposium reports, hypothesis formation and commentaries on: acute/chronic inflammation; mediators of inflammation; cellular processes; molecular mechanisms; pharmacology and novel anti-inflammatory drugs; clinical conditions involving inflammation. The manuscript management system is completely online and includes a very quick and fair peerreview system. Visit http://www.dovepress.com/testimonials.php to read real quotes from published authors. 